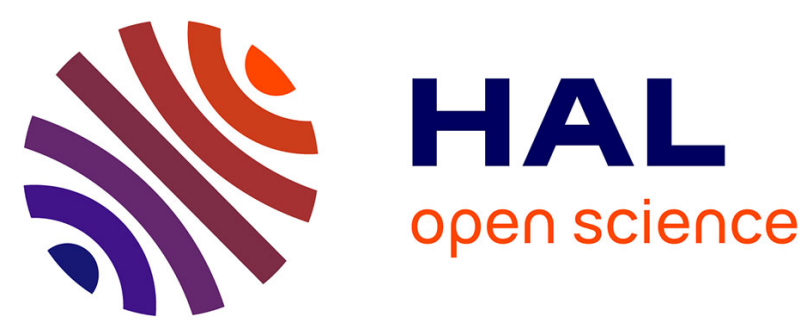

\title{
Corrosion investigation of fire-gilded bronze involving high surface resolution spectroscopic imaging
}

Giulia Masi, Cristina Chiavari, José Avila, Jérôme Esvan, Simona Raffo, Maria Chiara Bignozzi, Maria C. Asensio, Luc Robbiola, Clara Martini

\section{- To cite this version:}

Giulia Masi, Cristina Chiavari, José Avila, Jérôme Esvan, Simona Raffo, et al.. Corrosion investigation of fire-gilded bronze involving high surface resolution spectroscopic imaging. Applied Surface Science, 2016, 366, pp.317-327. 10.1016/j.apsusc.2016.01.101 . hal-01494641

\author{
HAL Id: hal-01494641 \\ https://hal.science/hal-01494641
}

Submitted on 23 Mar 2017

HAL is a multi-disciplinary open access archive for the deposit and dissemination of scientific research documents, whether they are published or not. The documents may come from teaching and research institutions in France or abroad, or from public or private research centers.
L'archive ouverte pluridisciplinaire HAL, est destinée au dépôt et à la diffusion de documents scientifiques de niveau recherche, publiés ou non, émanant des établissements d'enseignement et de recherche français ou étrangers, des laboratoires publics ou privés. 


\section{OATAO \\ Open Archive Toulouse Archive Ouverte}

\section{Open Archive TOULOUSE Archive Ouverte (OATAO)}

OATAO is an open access repository that collects the work of Toulouse researchers and makes it freely available over the web where possible.

This is an author-deposited version published in : http://oatao.univ-toulouse.fr/ Eprints ID : 16707

To link to this article : DOI:10.1016/j.apsusc.2016.01.101 URL : http://dx.doi.org/10.1016/j.apsusc.2016.01.101

To cite this version : Masi, Giulia and Chiavari, Cristina and Avila, José and Esvan, Jérôme and Raffo, Simona and Bignozzi, Maria Chiara and Asensio, Maria C. and Robbiola, Luc and Martini, Clara Corrosion investigation of fire-gilded bronze involving high surface resolution spectroscopic imaging. (2016) Applied Surface Science, vol. 366. pp. 317-327. ISSN 0169-4332

Any correspondence concerning this service should be sent to the repository administrator: staff-oatao@,listes-diff.inp-toulouse.fr 


\title{
Corrosion investigation of fire-gilded bronze involving high surface resolution spectroscopic imaging
}

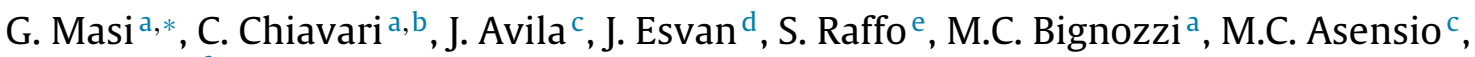 \\ L. Robbiola ${ }^{\mathrm{f}}$, C. Martini ${ }^{\mathrm{g}}$ \\ a Dipartimento di Ingegneria Civile, Chimica, Ambientale e dei Materiali, Università di Bologna, via Terracini 28, 40131 Bologna, Italy \\ b C.I.R.I. (Centro Interdipartimentale Ricerca Industriale) Meccanica Avanzata e Materiali, Università di Bologna, Bologna, via Terracini 28, 40131 Bologna, \\ Italy \\ ' Synchrotron SOLEIL, L'Orme des Merisiers, 91190 Saint-Aubin, France \\ d Centre Interuniversitaire de Recherche et d'Ingénierie des Matériaux, Université de Toulouse, 4 allée Emile Monso, 31030 Toulouse, France \\ e Dipartimento di Chimica Industriale "Toso Montanari”, Università di Bologna, viale Risorgimento 4, 40136 Bologna, Italy \\ f TRACES Lab (CNRS UMR5608), Université Toulouse Jean-Jaurès, 5, allées Antonio-Machado, 31058 Toulouse, France \\ ${ }^{g}$ Dipartimento di Ingegneria Industriale, Università di Bologna, viale Risorgimento 4, 40136 Bologna, Italy
}

Keywords:

Fire gilded bronze

Corrosion

Chemical imaging

Synchrotron radiation

Photoemission

Artworks

XPS

Decuprification

\begin{abstract}
A B S T R A C T
Gilded bronzes are often affected by severe corrosion, due to defects in the Au layer and $\mathrm{Au} / \mathrm{Cu}$ alloy galvanic coupling, stimulated by large cathodic area of the gilded layer. Galvanic corrosion, triggered by gilding defects, leads to products growth at the $\mathrm{Au}$ /bronze interface, inducing blistering or break-up of the Au layer. In this context, fire-gilded bronze replicas prepared by ancient methods (use of spreadable $\mathrm{Au}-\mathrm{Hg}$ paste) was specifically characterised by compiling complementary spectroscopic and imaging information before/after accelerated ageing with synthetic rain. Fire-gilded bronze samples were chemically imaged in cross-section at nano-metric scale $(<200 \mathrm{~nm})$ using high energy and lateral resolution synchrotron radiation photoemission (HR-SRPES) of core levels and valence band after conventional characterisation of the samples by Glow Discharge optical Emission Spectroscopy (GD-OES) and conventional X-ray photoelectron spectroscopy (XPS). We have found a net surface enrichment in $\mathrm{Zn}$ and Sn after fire-gilding and presence of metallic $\mathrm{Hg}, \mathrm{Pb}$ and $\mathrm{Cu}$ within the Au layer. Moreover, the composition distribution of the elements together with their oxidation has been determined. It was also revealed that metallic phases including $\mathrm{Hg}$ and $\mathrm{Pb}$ remain in the gilding after corrosion. Moreover, selective dissolution of $\mathrm{Zn}$ and $\mathrm{Cu}$ occurs in the crater due to galvanic coupling, which locally induces relative Sn species enrichment (decuprification). The feasibility advantages and disadvantages of chemical imaging using HR-SRPES to study artworks have been investigated on representative replicas.
\end{abstract}

\section{Introduction}

\subsection{System under investigation}

In outdoor conditions, gilded bronzes (widely used in historical monuments and in architectural elements) are often affected by severe corrosion of the bronze substrate, due to the presence of pores and defects in the gilding layer. In particular, degradation of gilded bronze is induced by galvanic coupling between

\footnotetext{
* Corresponding author. Tel.: +39 051 2090361; fax: +39 0512090322.

E-mail addresses: giulia.masi5@unibo.it(G. Masi), cristina.chiavari@unibo.it (C. Chiavari), jose.avila@synchrotron-soleil.fr (J. Avila), jerome.esvan@ensiacet.fr (J. Esvan), simona.raffo2@unibo.it (S. Raffo), maria.bignozzi@unibo.it (M.C. Bignozzi), maria-carmen.asensio@synchrotron-soleil.fr (M.C. Asensio), robbiola@univ-tlse2.fr (L. Robbiola),carla.martini@unibo.it (C. Martini).
}

bronze and gold. Defects such as thickness variation and pores in the gilding layer are mostly due to the gilding procedure. The main gilding methods used in antiquity were based (i) on the application of gold foil or leaf, (ii) on selective leaching of elements not as noble as gold (the so-called "depletion gilding" method) or (iii) on the use of spreadable gold-mercury amalgam paste, followed by mercury evaporation, as described in several papers [1-3]. In the present paper, the investigation is focused on amalgam-gilded (or "fire-gilded") bronze for which, after mercury evaporation, the matte gold-rich layer must be "burnished" (i.e. plastically deformed and compacted) by a smooth and hard tool (e.g. agate stone), so as to obtain a shiny surface [4]. This technological sequence produces a gilding layer with peculiar features. The most relevant characteristic is the presence of residual mercury (usually $\mathrm{Hg}$ concentration ranges from about 7 to $10 \mathrm{wt}$.\% in the gilding layer, although values up to $17 \mathrm{wt} . \%$ were also reported [4]), but also 
$\mathrm{Cu}-\mathrm{Au}$ interdiffusion due to heating for mercury evaporation [1] and the detrimental influence of alloying elements such as $\mathrm{Pb}$ on the gilding process [4] should be mentioned.

In a previous paper [5], we characterised quite extensively a fire-gilded quinary bronze $(\mathrm{Cu}-\mathrm{Sn}-\mathrm{Zn}-\mathrm{Pb}-\mathrm{Sb})$ in the as-gilded condition, obtained according to ancient recipes. Specifically, Focused Ion Beam (FIB) milling followed by cross-section observations, both by field emission SEM and by ion channelling contrast with $\mathrm{Ga}^{+}$, clearly showed the morphology of the Au-rich layer, partly compacted by burnishing but still retaining sub-micrometric porosity. It was also possible to reveal annealing twins in the recrystallised microstructure of the Au-rich layer, as well as the strain-hardened (hence very reactive) layer in the bronze immediately beneath the gilding. This layer consisted of small grains elongated in the direction of material flow due to mechanical polishing of the bronze before gilding. However, it was not possible to make detailed investigations, mainly due to the limits of the conventional X-ray spectrometry technique using $\mathrm{Mg}$ or $\mathrm{Al}$ anodes.

As regards the corrosion of fire-gilded bronzes, the Paradise Door (i.e. the Eastern door of the Baptistery of Florence, created by Lorenzo Ghiberti, 1425-1452) is a famous example [6]. This masterpiece was exposed to outdoor atmosphere in Florence, Italy, since its production until the Arno flood in 1966. As for many others gilded monuments, such as the horses of Saint Mark's basilica in Venice [7], the growth of corrosion products at the gold/bronze interface (with the formation of characteristic corrosion craters) led to blistering or break-up and loss of the gold layer [6,8]. The corrosion products detected beneath the gold layer in the case of Ghiberti's Paradise Door mainly consisted of copper oxide, basic sulphates and copper carbonates [9], with lesser amounts of chlorides and nitrates [10]. Furthermore, due to the action of acid rains, copper salts also dissolved and diffused above the fire-gilded surface, where brochantite, antlerite, paratacamite and copper hydroxyl nitrate [11] were identified by X-Ray Diffraction and IR spectroscopy. The presence of soluble nitrate-based compounds is often attributed to interaction with the polluted urban atmosphere, but they were also hypothesised to derive from residues of bronze pickling reagents used in the ancient past by goldsmiths before application of the gold-mercury paste, for improving the adhesion of the gilding layer on bronze [11].

The presence of several corrosion products, including hygroscopic compounds at the gold/bronze interface, makes fire-gilded bronzes quite unstable and complex systems [9,12,13], requiring specific restoration and conservation procedures [8]. In particular, cleaning procedures based both on chemical and on laser methods were applied $[11,14,15]$. After cleaning, conservation actions must be implemented on gilded bronze artworks to ensure their long-term corrosion protection. Both preventive techniques, such as microclimate control $[9,16]$ and use of coatings and inhibitors $[12,17,18]$, were investigated. In order to help microclimate control, specific sensors based on the measurement of galvanic currents in gold/bronze couples proved to be useful in finding the most suitable climatic parameters which ensure negligible corrosion rates [16].

Even if the main phenomenological aspects of gilded bronze corrosion are known, an improved characterisation of this multilayer system and the involved phenomena of decay is required, in order to pursue a deeper understanding of the corrosion mechanism, which is always a basic requirement for developing effective conservation strategies. Therefore, in the present work the same fire-gilded bronze as in the previous paper [5], was prepared according to ancient methods, so as to mimic the typical microstructure and morphology of amalgam-gilded bronzes. Ageing in conditions closely simulating outdoor exposure in runoff conditions (dropping tests [19]) was applied and these fire-gilded bronze samples were preliminary characterised by microscopy and micro-spectroscopy techniques (FIB-FEG/SEM, EDS, micro-Raman) [5].

\subsection{General XPS background}

X-ray photoelectron spectroscopy (XPS) has been applied since more than thirty years to ancient bronzes and patinas, in order to analyse the chemical state of elements on the outermost surfaces and (by $\mathrm{Ar}^{+}$sputtering) to explore depth profile [20-22]. However, its use in cultural heritage materials science has been initially restricted, due to experimental constraints linked to sample size, analysed area (typically larger than $300 \mu \mathrm{m}$ in diameter) but also to charge effects linked to weakly conducting surfaces [21,22]. This technique was often coupled to scanning Auger microscopy (Auger electron spectroscopy-AES) as an associate method highlighting the differences in the microchemical composition thanks to a smaller spatial resolution compared to XPS techniques [20-24].

Since the last fifteen years, the improvement in detection sensibility of XPS analyser and to the needs to accurately relate chemical binding to elemental or structural information led to more investigations on synthetic materials to be carried out. These investigations were mainly focused on chemical transformation of polished or artificially corroded $\mathrm{Cu}-\mathrm{Sn}(\mathrm{Zn}, \mathrm{Pb})$ bronzes in different conditions-as for example, in atmosphere under $\mathrm{SO}_{2}$ or $\mathrm{H}_{2} \mathrm{~S}$ gas pollution [25-28], in $\mathrm{NaCl}$ aqueous solution [29,30], in soil [31,32], from particular chemical solutions [33,34], but also related to the identification of specific copper or organic products $[24,35,36]$ or on the efficiency of conservation protective treatments $[37,38]$. On ancient artefacts, XPS investigation was often associated to other analytical techniques (EDS-SEM, XRD, PIXE, SIMS, LA-MS) [31,39-44]. XPS analysis usually were performed on surface fragments, sometimes coupled to depth profile measurement from $\mathrm{Ar}^{+}$ sputtering $[21,22,39,40]$ or laser ablation [44]. It should be noticed that several studies investigated the effect of $\mathrm{X}$-ray beam or $\left(\mathrm{Ar}^{+}\right)$ ion sputtering on the surface evolution $[21,24,26,28,39,41]$. They revealed that lead carbonate species as well as copper sulphate or copper oxide can be reduced, which can cause the interpretation of XPS and AES to be problematic for copper species. XPS was also seldom conducted on thick corrosion layers from cross-sections [31]. As regards mercury-amalgam plating on ancient bronzes, only very few studies applying XPS have been performed. In [45], surface analysis of several fragments of gilded copper base alloys clearly demonstrated the importance to combine surface analytical techniques helping to refine data on both the manufacturing process and the degradation state.

Recently, a multi-analytical approach including conventional XPS and synchrotron radiation-(SR) based techniques was applied to two leaded bronzes, revealing all the interest for getting mapping of the surface chemistry of the bronze at a sub-micrometric spatial resolution $[41,42]$. This global approach has been recently extended to synchrotron X-ray photoelectron spectroscopy and $\mathrm{X}$-ray absorption spectroscopy on mercury gilded silver plates, differently coloured according to different applied treatments based on mediaeval writings [46]. This study pointed out the interest to use SR as a highly powerful X-ray source for performing XPS surface measurements.

\subsection{Aim of the work}

In the present paper, the main aim is to evaluate the application of highly energy and lateral resolution synchrotron radiation photoemission (HR-SRPES) for obtaining spatially resolved information on corroded bronze samples at a sub-micrometric level $(<500 \mathrm{~nm})$. In particular, special attention was paid to the mapping of chemical species and their state of oxidation. To this aim, state of the art 
chemical mapping using HR-SRPES has been tested here for the first time on cross-sections of typical corrosion craters, at the interface between the gold layer and the bronze substrate.

Here, also based on a multi-analytical approach involving the use of other analytical methods (EDS-SEM, GD-OES and conventional XPS), from surface as well as cross-section analysis, the objectives were: (i) to clarify the distribution of elements in the as-gilded bronze, in order to understand the role of bronze alloying elements $(\mathrm{Cu}, \mathrm{Sn}, \mathrm{Zn}, \mathrm{Pb})$ as well as the role of residual $\mathrm{Hg}$ in the structure of the gilding layer and (ii) to investigate the interactions between elements in the alloy/gilding layer system and the environmental elements, mainly $\mathrm{O}$, and also $\mathrm{S}$ and $\mathrm{Cl}$ elements.

\section{Materials and methods}

\subsection{Preparation of fire-gilded bronze samples}

The composition of the bronze, cast in stone moulds and then fire-gilded, is similar to those of Renaissance artefacts: $\mathrm{Sn}: 3.3, \mathrm{Zn}$ : 1.5, Pb: 1.0, Sb: 0.2 wt.\%, Cu to balance (Sn: 1.81, Zn: 1.49, Pb: 0.31, Sb: 0.11 at.\%). The alloy exhibits a dendritic microstructure of cored $\alpha$-Cu solid solution, typical of as-cast bronze (with $\mathrm{Sn}$ - and Sb-local enrichment in the interdendritic spaces), also including globules of $\mathrm{Pb}$ as described in [47]. Residual porosity and shrinkage cavities were uniformly distributed in the alloy.

Fire-gilding was carried out after mechanical polishing ( $\mathrm{SiC} 180$ grit) of the cast bronze surface followed by nitric acid pickling ( $10 \mathrm{wt} . \%$ of $\mathrm{HNO}_{3}$ in deionised water) and rinsing in water. The polished and pickled surface was then covered with $\mathrm{Au}-\mathrm{Hg}$ (1:8 wt.\%) amalgam paste (according to the recipe by Benvenuto Cellini in his treatises on goldsmithing and sculpture (1568) [48]) and then heated by an open flame, so as to vaporise $\mathrm{Hg}$. Subsequently, the gilded surface was burnished by an agate tool (using olive oil as a lubricant), in order to densify the porous layer and produce a smooth and shiny surface with a golden appearance. No other goldcolouring procedure, as those described in [46], was applied on the as-gilded surface. The thickness of the mercury gilding layer was estimated by SEM observation of cross sections.

\subsection{Accelerated ageing in runoff conditions (dropping tests)}

Fire-gilded bronze specimens $\left(2.5 \times 5.0 \mathrm{~cm}^{2}\right)$ were exposed to synthetic rain $(\mathrm{pH}=4.3)$ by dropping tests with a total Time of Wetness (TOW) of 30 days. The dropping tests simulate unsheltered exposure to rainwater (runoff conditions). In this test the rain solution was periodically dropped onto $45^{\circ}$ inclined specimens, with alternated cycles of 2-days dropping/1-day drying and 3-days dropping/1-day drying, selected on the basis of environmental data from the monitoring stations in Bologna, Italy [19].

As reported in [5], the artificially aged samples produced by dropping with TOW of 30 days can be used for a deeper investigation of corrosion process. This method produces crater-like corrosion features at the interface between the gilding layer and bronze, comparable to historical reference artefacts.

\subsection{Characterisation of fire-gilded samples}

The free surface of fire-gilded bronze was observed by 3DDigital microscopy. On the free surface of gilded bronze, also Glow Discharge-Optical Emission Spectroscopy (GD-OES) concentration profiles were measured, after gentle rinsing with ethanol, so as to remove surface contamination. GD-OES analysis was carried out with a Grimm-style glow discharge lamp in DC mode. The internal diameter of the tubular anode (hence the analysed area in each measurement) was $2.5 \mathrm{~mm}$ and the in-depth spatial resolution during depth concentration profiles (perpendicular to the surface) is about $50 \mathrm{~nm}$. The Grimm-type atomisation/excitation source was evacuated by a rotary pump to a final pressure of $0.05 \mathrm{hPa}$. After evacuation, flowing argon as a working gas (99.995\% purity) was introduced to a constant pressure of $3 \mathrm{hPa}$. Constant discharge conditions (voltage $900 \mathrm{~V}$ and current $9 \mathrm{~mA}$ ) were used in order to maintain a constant sputtering rate. The crater depths were measured by stylus profilometry after the GD-OES measurements, in order to check the sputtering rates.

Conventional metallographic techniques (i.e. cold mounting in conductive resin) were used, for the preparation of cross sections. The gilding layer and the corrosion features at the gold/bronze interface were characterised by a coupled system SEM/EDSRaman SCA (Scanning Electron Microscopy with Energy Dispersive Spectroscopy and Raman microprobes, Structural and Chemical Analyser, $\lambda=514.5 \mathrm{~nm}$, power: $5 \mathrm{~mW}$ ).

The characterisation of the interphases in the cross-sections was performed by HR-SRPES with an excitation energy of $850 \mathrm{eV}$ (therefore it was not possible, by HR-SRPES, to explore binding energy contributions such as those from $\mathrm{Cu} 2 \mathrm{p}_{3 / 2}$ and $\mathrm{Zn} 2 \mathrm{p}_{3 / 2}$ at about 932-934 and $1022 \mathrm{eV}$, respectively). HR-SRPES experiments were conducted in the ANTARES beamline at the SOLEIL synchrotron.

Considering a thickness of the Au layer lower than $10 \mu \mathrm{m}$, crosssection of the samples were analysed taking advantage of ANTARES beam resolution. Imaging of polished cross-sections was carried out with the high resolution R4000 Scienta hemispherical analyser and a set of Fresnel Zone Plates (FZP), able to focalise the beam spot up to a few tenths of nanometers in spatial resolution. The main difference of the ANTARES microscope from other conventional ARPES instruments is that the specimens can be mounted on a highprecision plate that ensures their nanoscale positioning in the $x, y$ and $z$ directions $[49,50]$. The pass energy was fixed at $100 \mathrm{eV}$ with a step at $0.05 \mathrm{eV}$ for core levels. Investigated core levels were limited to a few localised spots, due to the available synchrotron beam time, which was mostly used for time-consuming high-resolution photoelectron spectroscopy (HR-SRPES) maps. A surface cleaning using He ion bombardment was applied prior XPS measurements.

Complementary conventional XPS analyses were also carried out on the top of the fire-gilded surfaces. The photoelectron emission spectra were recorded using a monochromatised $\mathrm{Al} \mathrm{K \alpha}$ ( $h v=1486.6 \mathrm{eV}$ ) source on a ThermoScientific K-Alpha system. The $\mathrm{X}$-ray spot size was about $400 \mu \mathrm{m}$. The pass energy was fixed at $30 \mathrm{eV}$ with a step of $0.1 \mathrm{eV}$ for core levels. Ionic sputtering of the surfaces was made by $\mathrm{Ar}^{+}$ion beam accelerated under $2 \mathrm{keV}$ low current. XPS spectra were recorded in direct N (Ec).

For both XPS systems (HR-SRPES and ThermoScientific K-Alpha XPS), the in-depth resolution is of a few $\mathrm{nm}$. The spectrometer energy calibration was made using the $\mathrm{Au} 4 \mathrm{f}_{7 / 2}(\mathrm{BE}=84.0 \pm 0.1 \mathrm{eV})$ photoelectron line and the $C 1 \mathrm{~s}$ value of adventitious carbon $(\mathrm{BE}=284.8 \pm 0.2 \mathrm{eV})$ when no Au was present. The different core levels investigated were $\mathrm{C} 1 \mathrm{~s}, \mathrm{O} 1 \mathrm{~s}, \mathrm{~S} 2 \mathrm{p}, \mathrm{Cl} 2 \mathrm{p}, \mathrm{Cu}$ and $\mathrm{Zn}$ : 3p (2p only for K-Alpha XPS system), Sn 3d, Sb 3d, Au $4 f$ and Pb 4 f. The background signal was removed using Shirley method. The photoelectron peaks were analysed by Gaussian/Lorentzian $(G / L=30 \%)$ peak fitting. The atomic concentrations were determined with an accuracy of $10 \%$ from photoelectron peak area, using the atomic sensitivity factors reported by Scofield, taking into account the transmission function of the analyser according to the energies applied (850 eV for HR-SRPES and 1486.6 eV for K-Alpha XPS).

\section{Results}

\subsection{As-gilded bronze}

The topographic image of the as-gilded surface (Fig. 1a) shows residual grooves (from about 5 to $10 \mu \mathrm{m}$ deep) due to mechanical 


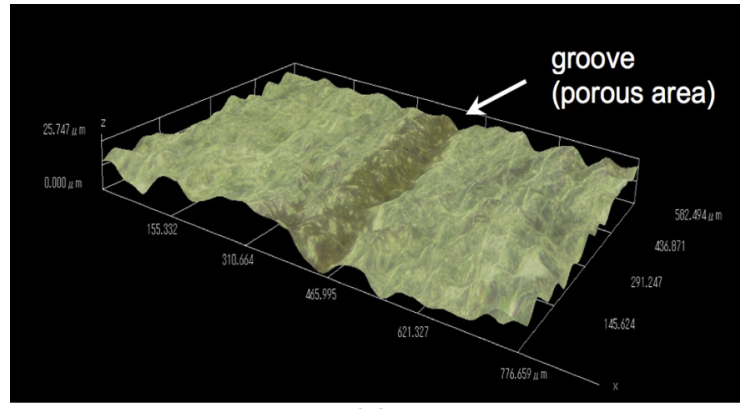

(a)

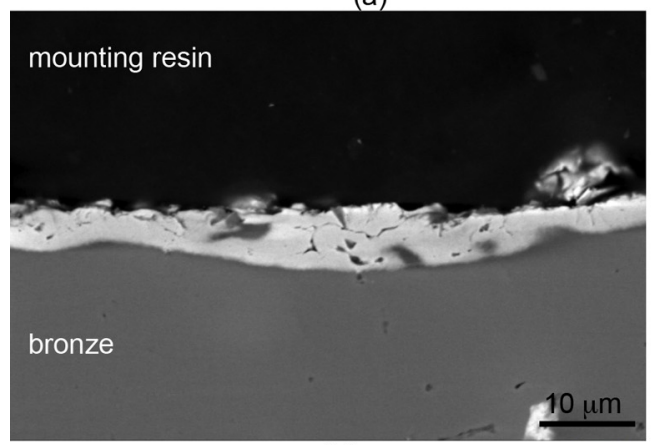

(c)

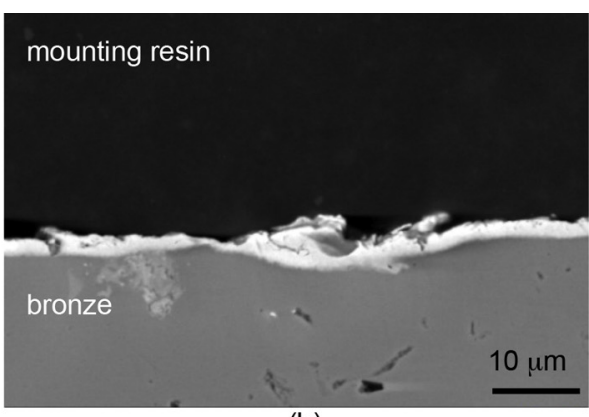

(b)

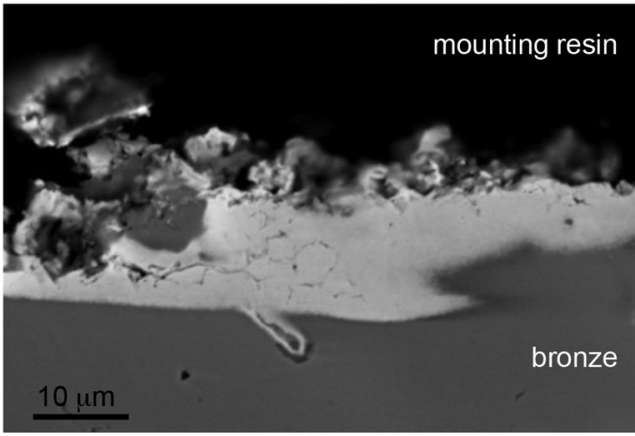

(d)

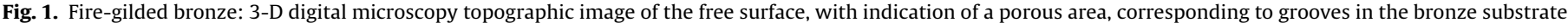

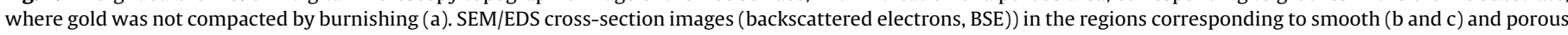
areas (d). The fire-gilded layer is the white layer in the central area of each BSE image.

polishing before gilding. This peculiar feature leads to two typical surface morphologies: smooth and flat areas (where the burnishing procedure successfully compacted the gilded layer after Hg evaporation) and porous areas (due to insufficient burnishing). In fact, in the porous areas, some grooves were too deep to allow full densification of the gilded layer. Cross-section images in Fig. 1b-d shows that the thickness of the gilded layer is remarkably higher (around $10 \mu \mathrm{m}$ thick) in porous areas by comparison to the smooth ones (about $2 \mu \mathrm{m}$ ).

It must be taken into account that the gold layer thickness may be overestimated due to smearing of soft gold on hard bronze during metallographic polishing [1]), whereas, for the same reason, the gold porosity may be underestimated. As detailed in [5], FIB milling and FEG-SEM observations allowed detailed morphological characterisation in terms of compactness and porosity, confirming that smooth areas (i.e. areas where the burnishing procedure was fully effective) display lower thickness and higher density by comparison to porous areas on the grooves.

The typical elemental distribution of the fire-gilded bronze before corrosion is shown in Fig. 2. Mercury ( $\mathrm{Hg}$ ) was detected in the gilded layer, but also alloying elements from the bronze substrate, such as $\mathrm{Sn}$ and $\mathrm{Zn}$. The presence of $\mathrm{N}$ in the gilded layer is more probably due to the previously described nitric acid pickling procedure.

However, it is difficult to determine accurately the elemental distribution of $\mathrm{Au}, \mathrm{Hg}, \mathrm{Pb}, \mathrm{Sn}$ and $\mathrm{Sb}$ in the gilded layer by SEMEDS, due to the limited spatial resolution of the X-ray source but also to the overlapping of the principal emission peaks ( $M$ peaks of $\mathrm{Au}, \mathrm{Hg}$ and $\mathrm{Pb}$ and $\mathrm{L}$ peaks of $\mathrm{Sn}$ and $\mathrm{Sb}$ ). Therefore, a more detailed characterisation was carried out by GD-OES concentration profiles as well as by conventional XPS and by HR-SRPES imaging.

The GD-OES concentration profiles are given in Fig. 3. In the outermost part of the gilding $(<0.25 \mu \mathrm{m})$, an enrichment of $\mathrm{Hg}$ was revealed: $\mathrm{Hg}$ concentration increases with decreasing distance from the surface, most likely due to diffusion of $\mathrm{Hg}$ towards the outer surface during the fire heating procedure. This superficial $\mathrm{Hg}$ enrichment is accompanied by a marked enrichment in $\mathrm{Sn}$ and $\mathrm{Zn}$ by comparison to $\mathrm{Cu}$ and $\mathrm{Pb}$ also present in the gilded layer (Fig. 3, inlay). This phenomenon vanished after the maximum of Au concentration (thickness: $0.4-0.5 \mu \mathrm{m}$ ) and it was most likely linked to the effect of the mercury evaporation during the heating step. The gradual variation of the alloying elements, coupled with the gradual decrease of $\mathrm{Au}$ across the interface between the gilding layer and the bronze substrate, is surely also related to the large size $(2.5 \mathrm{~mm})$ of the analysed surface area, averaging the variable thickness of the gilding.

Considering $\mathrm{Cu}$ and $\mathrm{Au}$ GD-OES profiles across the gilding layer, showing a gradual increase of $\mathrm{Cu}$ concentration starting from the surface, coupled with the gradual decrease of $\mathrm{Au}, \mathrm{Cu}-\mathrm{Au}$ interdiffusion can be hypothesised, because these elements are known to intermix readily when solid-state diffusion takes place [51]. On going from the outermost surface towards the bulk, the GD-OES profiles show the presence of $\mathrm{Cu}$ also in the most external regions of the gilding (far from the interface, hence in regions where the variable thickness of the gilding did not affect the GD-OES data), so confirming the hypothesis of interdiffusion. The ability of the heating step (carried out here so as to remove $\mathrm{Hg}$ from the fire-gilded layer) to induce interdiffusion of $\mathrm{Cu}$ and $\mathrm{Au}$, was also observed by other authors in the general case of gilded artefacts involving heating [1,4,6,52-54].

The results of XPS measurements performed on the as-gilded bronze surface, before and after $\mathrm{Ar}^{+}$etching, are given in Table 1, which highlights a high content of environmental-related elements including $\mathrm{C}, \mathrm{N}, \mathrm{O}, \mathrm{S}$ and $\mathrm{Si}$, which decreased in intensity after $\mathrm{Ar}^{+}$ etching. $\mathrm{C} 1 \mathrm{~s}$ is linked to carbonyl pollutants also including $\mathrm{C}-\mathrm{N}$ species. It is interesting to notice the relatively high proportion of nitrogen (2.4 at.\%), which cannot be ascribed to nitrate but could be related to $\mathrm{C}$ and $\mathrm{H}$ (BE core level at $\sim 399.5 \mathrm{eV}$ [55]). Also regarding sulphur, the peak of $S 2 p$ is in two states, corresponding to sulphate and sulphide. No chlorides were detected.

On the gilded surface, a high amount of $\mathrm{Hg}$ was also revealed, decreasing after the ion bombardment (Table 1), in agreement 

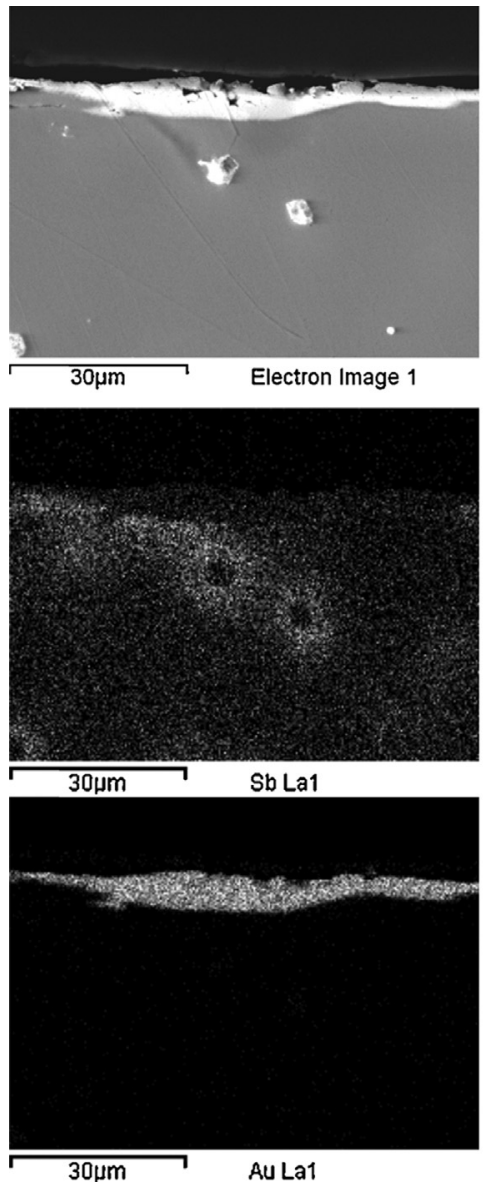
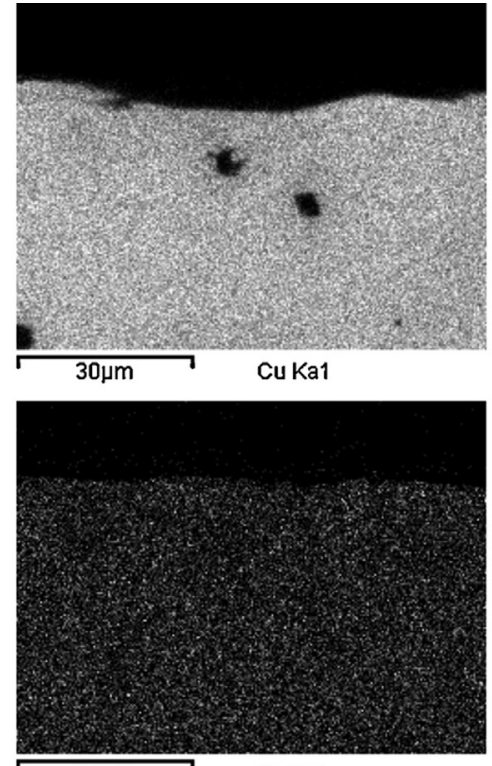

$30 \mu \mathrm{m}$

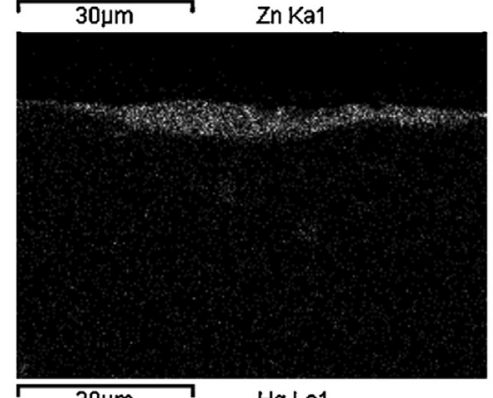

$30 \mu \mathrm{m} \quad \mathrm{Hg} \mathrm{La}$

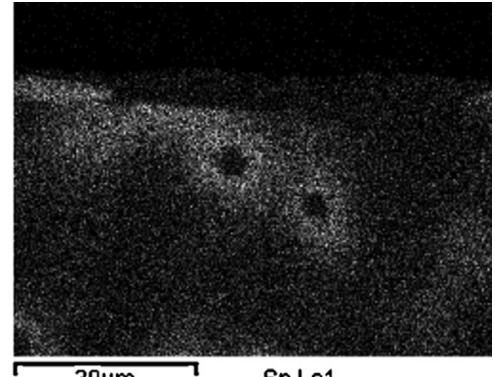

$30 \mu \mathrm{m} \quad \mathrm{SnLa1}$

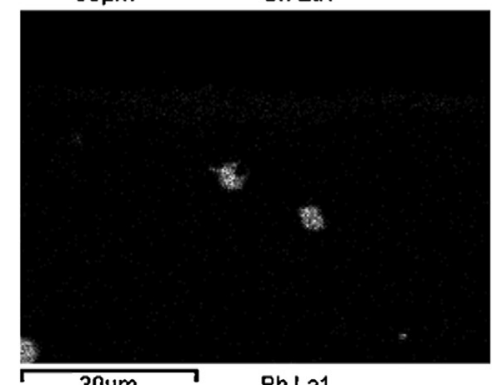

30um Pb La1

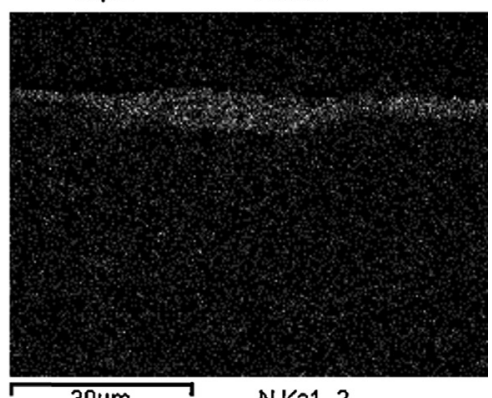

$30 \mu \mathrm{m} \quad \mathrm{NKa}$

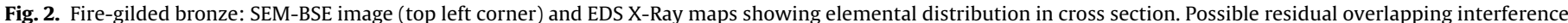
for EDS X-ray M peaks of $\mathrm{Au}, \mathrm{Hg}$ and $\mathrm{Pb}$, as well as for $\mathrm{L}$ peaks of $\mathrm{Sn}$ and $\mathrm{Sb}$.

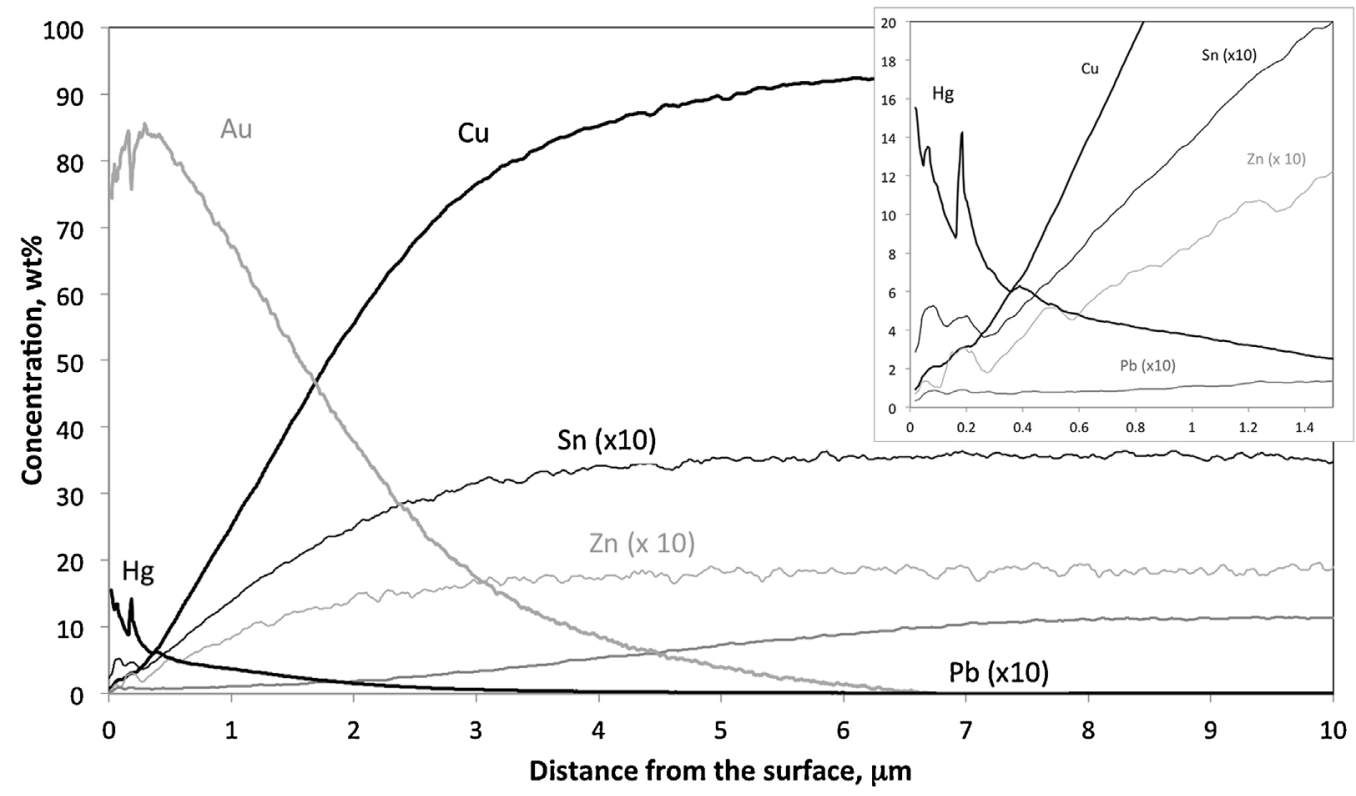

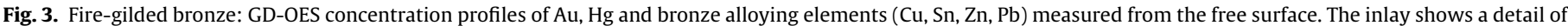
the concentration variation for the outer zone of the gilding $(<1.5 \mu \mathrm{m})$.

with GD-OES data (Fig. 3). Also the enrichment in Zn by comparison to the $\mathrm{Cu}$ initial content of the bronze was confirmed, $(\mathrm{Zn} / \mathrm{Cu}$ atomic ratio increases from 0.015 (alloy) to 0.17 (top surface)).
XPS core level measurements showed that these elements are in the metallic $(\mathrm{Au}, \mathrm{Hg})$ or in the oxidised state $(\mathrm{Sn}, \mathrm{Zn})$ or under both states $(\mathrm{Cu}, \mathrm{Pb})$. The metallic $\mathrm{Cu}(0)$ component in the outermost layer of the gilded surface is confirmed from the calculation 
Table 1

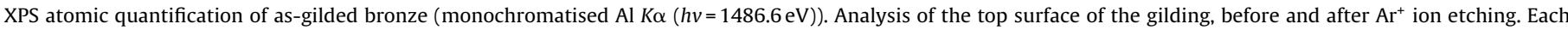
value was normalised to Au atomic content $(\mathrm{Au}=1)$.

\begin{tabular}{|c|c|c|c|c|c|c|c|c|c|c|}
\hline & $\begin{array}{l}\text { Au4ff } \\
\text { Metal }\end{array}$ & $\begin{array}{l}\text { Hg } 4 f_{7 / 2} \\
\text { Metal }\end{array}$ & $\mathrm{C} 1 \mathrm{~s}$ & $\begin{array}{l}\mathrm{N} 1 \mathrm{~s} \\
\mathrm{~N}-\mathrm{C}\end{array}$ & 01s & $\begin{array}{l}\text { S2p } \\
\text { Sulfide/sulfate }\end{array}$ & $\begin{array}{l}\mathrm{Cu} 2 \mathrm{p}_{3 / 2} \\
\mathrm{Cu}^{\circ}-\mathrm{Cu}(\mathrm{I}) / \mathrm{Cu}(\mathrm{II}) \text { oxide } / \mathrm{Cu}(\mathrm{II}) \text { hydroxide }\end{array}$ & $\begin{array}{l}\operatorname{Sn} 3 d_{5 / 2} \\
\operatorname{Sn}(I V)\end{array}$ & $\begin{array}{l}\mathrm{Zn} 2 \mathrm{p} 3 / 2 \\
\text { Oxide }\end{array}$ & $\begin{array}{l}\mathrm{Pb}_{4} \mathrm{f}_{7 / 2} \\
\text { Metal/oxide }\end{array}$ \\
\hline \multicolumn{11}{|l|}{ Before etching } \\
\hline Peak BE $(\mathrm{eV})$ & 84.0 & 100.0 & 284.6 & 399.7 & 531.9 & $162.4 / 169.0$ & $932.5^{*} / 933.5 / 934.9$ & 486.7 & 1022.1 & 136.9/138.6 \\
\hline at.\% & 4.9 & 0.5 & 74.0 & 2.4 & 15.4 & $0.7 / 0.4$ & $0.5 / 0.3 / 0.1$ & $<0.2$ & 0.3 & $0.1 / 0.2$ \\
\hline \multicolumn{11}{|c|}{ After etching (10 s $\mathbf{A r} \pm$ ) } \\
\hline Peak BE $(\mathrm{eV})$ & 84.0 & 100.0 & 284.7 & 399.2 & 532.0 & $162.9 / 168.9$ & $932.5^{*} / 933.4 / 934.9$ & 486.8 & 1022.3 & $136.8 / 138.7$ \\
\hline at.\% & 12.7 & 0.8 & 69.2 & 2.9 & 9.6 & $1.1 / 0.3$ & $1.1 / 1.1 / 0.2$ & $<0.2$ & 0.4 & $0.1 / 0.3$ \\
\hline \multicolumn{11}{|c|}{ Normalised (/Au at.\%) } \\
\hline Before etching & 1.00 & 0.10 & 15.10 & 0.49 & 3.14 & $0.14 / 0.08$ & $0.1 / 0.06 / 0.02$ & $<0.04$ & 0.06 & $0.02 / 0.04$ \\
\hline After etching & 1.00 & 0.06 & 5.45 & 0.22 & 0.75 & $0.09 / 0.02$ & $0.09 / 0.09 / 0.01$ & $<0.01$ & 0.03 & $0.01 / 0.02$ \\
\hline
\end{tabular}

$\mathrm{KE}(\mathrm{CuLMM})=918.1 \mathrm{eV} \alpha^{\prime}=1850.6 \mathrm{eV}$.

of the Auger parameter ( $\alpha^{\prime}$, Table 1$)$ and is significantly high. For $\mathrm{Pb}$, oxidised state is mainly found but a minor component is metallic even before ion etching, clearly indicating the presence of a metallic phase, probably alloyed with $\mathrm{Hg}$, within the gold layer. For $\mathrm{Sn}$, the signal intensity was at the limit of detection (around 0.2 at.\% after ion etching), therefore the exact oxidation state and the possible relative enrichment of $\mathrm{Sn}$ in the surface by comparison to Cu could not be determined.

These results point out that the fire-gilding process induced the $\mathrm{Hg}$ enrichment in the outer layer of the gilding, but also favoured the diffusion of $\mathrm{Sn}$ and $\mathrm{Zn}$ by comparison to $\mathrm{Cu}$ (inlay, Fig. 3). The XPS data also highlight the presence of metallic phases involving $\mathrm{Pb}$ but also $\mathrm{Cu}$. The metallic $\mathrm{Cu}(0)$ component on the top gilded surface remains the main oxidation state, as confirmed by the evaluation of its Auger parameter ( $\alpha^{\prime}$-Table 1): $\alpha^{\prime}=1850.6 \mathrm{eV}$ (both before and after etching), in good agreement with $\mathrm{Cu}(0)$ state $(1851 \pm 0.5 \mathrm{eV})$ [56].

These alloying elements ( $\mathrm{Sn}, \mathrm{Zn}$ ), present in the outermost part of the gilding layer, are potentially and preferentially reactive to preferential corrosion [19]. The presence of metallic Sn and $\mathrm{Zn}$ in the outer layer of the gilding may be related to stronger interactions of these elements with both $\mathrm{Au}$ and $\mathrm{Hg}$. In particular, both $\mathrm{Sn}$ and $\mathrm{Zn}$ form mercury amalgams and intermetallic compounds with Au and $\mathrm{Hg}$ [57]. Specifically, Au-Sn diffusion and compounds formation is well-documented in the field of electronic devices [51]. For Pb, only very low amounts of metallic $\mathrm{Pb}(0.07$ at.\%) were detected by XPS after etching on the top surface (Table 1 ). Pb was detected only in very low concentration by GD-OES in the outer part of the gilding layer (Fig. 3, inlay), not showing the same superficial enrichment trend as Sn and $\mathrm{Zn}$, notwithstanding the ability of this element to form $\mathrm{Hg}$ amalgam and Au-based intermetallics [57]. The low concentration of $\mathrm{Pb}$ in the outer part of the gilding could be due to the low amount and to the inhomogeneous distribution of $\mathrm{Pb}$ in the bronze alloy.

\subsection{Artificially corroded gilded bronze}

After artificial ageing, XPS measurements on the top of the gilded surface, before and after $\mathrm{Ar}^{+}$ion bombardment (Table 2), revealed a high content of light elements by comparison with the uncorroded surface. The main difference is related to an increase of $\mathrm{C}, \mathrm{O}$ and $\mathrm{S}$ elements, due to corrosion induced by the artificial rain solution. For carbon and oxygen, a marked increase corresponding to $\mathrm{C}-\mathrm{O}$ binding is found, which can be mainly ascribed to carbonate species ( $C$ at $\sim 289.3 \mathrm{eV}$ and $\mathrm{O}$ at $\sim 532 \mathrm{eV}$ ) [36]. After accelerated ageing, it was also found that $\mathrm{Hg}$ remains in the metallic state in the top gilded layer.

As regards the alloying elements of the bronze, $\mathrm{Cu}$ and $\mathrm{Pb}$ are always found within the surface. For $\mathrm{Cu}$, the metallic component remains present according to the Auger parameter estimation
(Table 2, $\alpha^{\prime}=1850.6 \mathrm{eV}$ after etching [56]). For Pb, several contributions are present and can be related to oxidised species (hydroxi-, sulphates and probably oxide) but also to metallic $\mathrm{Pb}$, which remains on the gilding layer in a very low amount (0.08 at.\% after etching). For $\mathrm{Zn}$ and $\mathrm{Sn}$, always by comparison to the uncorroded sample, a decrease of their amounts was observed, as revealed by their normalised atomic values $(/ \mathrm{Au})$ of Table 1 compared to Table 2 . $\mathrm{Sn}$ is oxidised, but the signal was barely detectable and no precise information could be given. However, these results showed that accelerated ageing induced a decrease of $\mathrm{Zn}$ content on the top surface, e.g. the oxidised $\mathrm{Zn}$ concentration before ageing was 0.03 (/Au), (Table 1 after etching) and decreased down to $0.01(/ \mathrm{Au})$, Table 2). No remarkable variation was observed for Hg. Similarly, also $\mathrm{Cu}$ was not significantly affected after ageing: the normalised $\mathrm{Cu}$ atomic ratio (/Au) was 0.19 for the as-gilded sample (Table 1 ) and 0.22 when corroded (Table 2). Therefore, both $\mathrm{Hg}$ and $\mathrm{Cu}$, probably in solid solution with $\mathrm{Au}$, remained in the top layer and were not completely dissolved after artificial ageing.

The cross-sections of the artificially corroded fire-gilded bronze revealed large craters under the fire-gilded layer as usually observed for this type of materials [9,10]. Elemental distribution is illustrated by EDS X-ray maps in Fig. 4. Concerning the fire-gilded layer, the contributions of $\mathrm{Au}, \mathrm{Hg}$ and $\mathrm{Pb}$ were not easy to separate on the basis of EDS data. Within the crater, corrosion was marked by a depletion of $\mathrm{Cu}$ and $\mathrm{Zn}$, with consequent relative enrichment of $\mathrm{Sn}$ and incorporation of oxygen species (Fig. 4).

HR-SRPES investigations were performed on a representative corrosion crater in the corroded gilded bronze sample.

In particular, two representative points were identified: point $A$ in the gilding layer and point B in the corrosion crater (see Fig. 5 for the localisation of points in the HR-SRPES maps).

The HR-SRPES analysis of the gilded layer confirmed the presence of $\mathrm{Pb}$ and $\mathrm{Cu}$, but also $\mathrm{Sn}$ and $\mathrm{Zn}$ (near the detection limit) within the gold layer. Fig. 6 shows core level spectra for $\mathrm{Hg}$ in the gilded layer after corrosion, indicating that $\mathrm{Hg}$ is still present also in the metallic state $\left(\mathrm{BE} \mathrm{Hg} 4 \mathrm{f}_{7 / 2}: 99.8 \mathrm{eV}\right)$. The same interpretation of core level was applied to $\mathrm{Pb}\left(\mathrm{BE} \mathrm{Pb} 4 \mathrm{f}_{7 / 2}: 136.5 \mathrm{eV}\right)$, not shown in Fig. 6.

As regards environmental elements inside the gilded layer, the overview XPS spectra did not show the presence of $\mathrm{S}$ and $\mathrm{Cl}$; only $\mathrm{C}$ and $\mathrm{O}$ were detected. The presence of $\mathrm{C}$ and $\mathrm{O}$ in the gilded layer could be related to the corrosion process but also to mounting resin contamination.

As regards alloying elements in the gilding layer, HR-SRPES showed the presence of metallic phases which can be still present after corrosion, as already observed also by conventional XPS surface analysis only on the top surface (Table 2). In fact, in the upper part of the gilding layer (at a few hundreds of $\mathrm{nm}$ from the surface, point $\mathrm{A}$ in Fig. 5), an $\mathrm{Au} / \mathrm{Hg}$ atomic ratio of about 15 was determined by atomic quantification from core level spectra (Table 3 ), in good 
Table 2

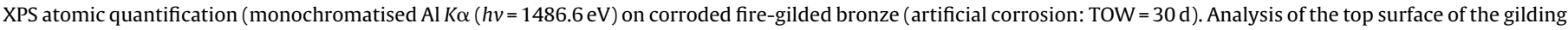
before and after $\mathrm{Ar}^{+}$ion etching. Each value has been normalised to $\mathrm{Au}$ atomic content $(\mathrm{Au}=1)$

\begin{tabular}{|c|c|c|c|c|c|c|c|c|c|c|}
\hline & Au $4 f_{7 / 2}$ & $\mathrm{Hg} 4 \mathrm{f}_{7 / 2}$ & $\mathrm{C} 1 \mathrm{~s}$ & $\mathrm{~N} 1 \mathrm{~s}$ & $01 \mathrm{~s}$ & S $2 p$ & $\mathrm{Cu} 2 \mathrm{p}_{3 / 2}$ & $\operatorname{Sn} 3 d_{5 / 2}$ & $\mathrm{Zn} 2 \mathrm{p}_{3 / 2}$ & $\mathrm{~Pb} 4 \mathrm{f}_{7 / 2}$ \\
\hline & Metal & Metal & & & & Sulfide/sulfate & $\mathrm{Cu}^{\circ}-\mathrm{Cu}(\mathrm{I}) / \mathrm{Cu}(\mathrm{II})$ oxide $/ \mathrm{Cu}(\mathrm{II})$ hydroxide & $\mathrm{Sn}(\mathrm{IV})$ & Oxide & Metal/oxide \\
\hline \multicolumn{11}{|c|}{ without etching } \\
\hline Peak BE $(\mathrm{eV})$ & 83.8 & 99.9 & 285.1 & 399.6 & 532.5 & $161.8 / 168.9$ & $932.3^{*} / 933.6 / 935.1$ & 486.2 & 1023.1 & $136.8 / 138.0$ \\
\hline at.\% & 4.7 & 0.2 & 66.1 & 2.3 & 22.7 & $1.3 / 1.0$ & $0.5 / 0.5 / 0.3$ & $<0.2(\mathrm{LD})$ & 0.1 & $0 / 0.1$ \\
\hline \multicolumn{11}{|c|}{ After etching (10 s $\mathrm{Ar} \pm$ ) } \\
\hline Peak BE $(\mathrm{eV})$ & 83.8 & 99.8 & 284.9 & 399.5 & 532.5 & $162.0 / 168.8$ & $932.3^{* *} / 933.5 / 935.1$ & 486.7 & 1022.3 & $136.8 / 138.4$ \\
\hline at.\% & 29.8 & 1.0 & 42.8 & 3.9 & 13.4 & $1.9 / 0.1$ & $4.5 / 1.7 / 0.2$ & $<0.2(\mathrm{LD})$ & 0.2 & $0.1 / 0.2$ \\
\hline \multicolumn{11}{|c|}{ Normalised (/Au at.\%) } \\
\hline Before etching & 1.00 & 0.04 & 14.06 & 0.49 & 4.83 & $0.28 / 0.21$ & $0.1 / 0.1 / 0.06$ & $<0.04$ & 0.02 & $0.00 / 0.02$ \\
\hline After etching & 1.00 & 0.03 & 1.43 & 0.13 & 0.45 & $0.06 / 0.03$ & $0.15 / 0.06 / 0.01$ & $<0.01$ & 0.01 & $0.00 / 0.01$ \\
\hline
\end{tabular}

LD: limit of detection.

${ }^{*} \mathrm{KE}(\mathrm{CuLMM})=918.1 \mathrm{eV} \alpha^{\prime}=1850.4 \mathrm{eV}-\mathrm{Cu}^{\circ} / \mathrm{Cu}^{+}$component

KE $(\mathrm{CuLMM})=918.3 \mathrm{eV} \alpha^{\prime}=1850.6 \mathrm{eV}-\mathrm{Cu}^{\circ}$.
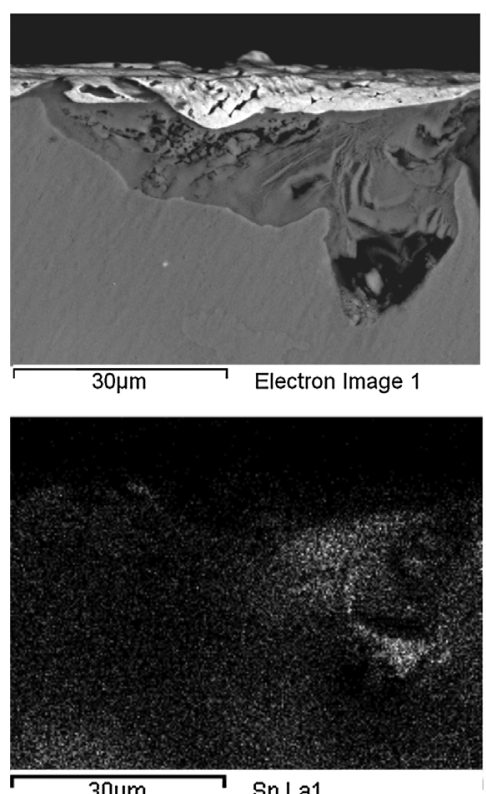

$30 \mu \mathrm{m}$ Sn La1

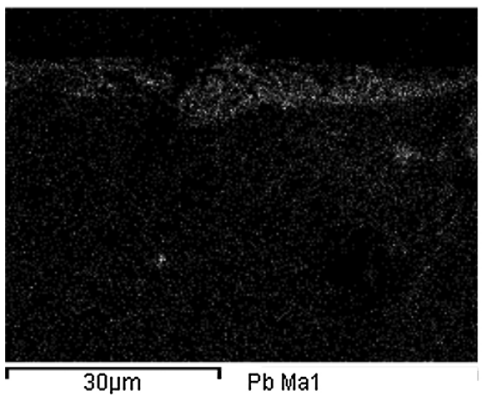

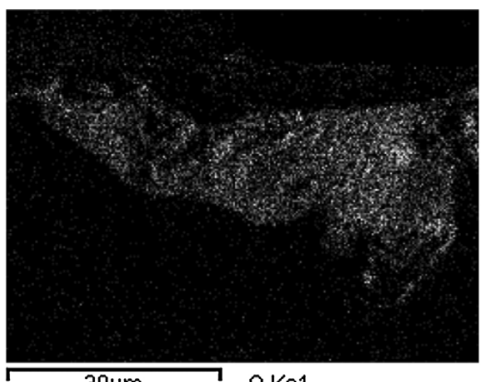
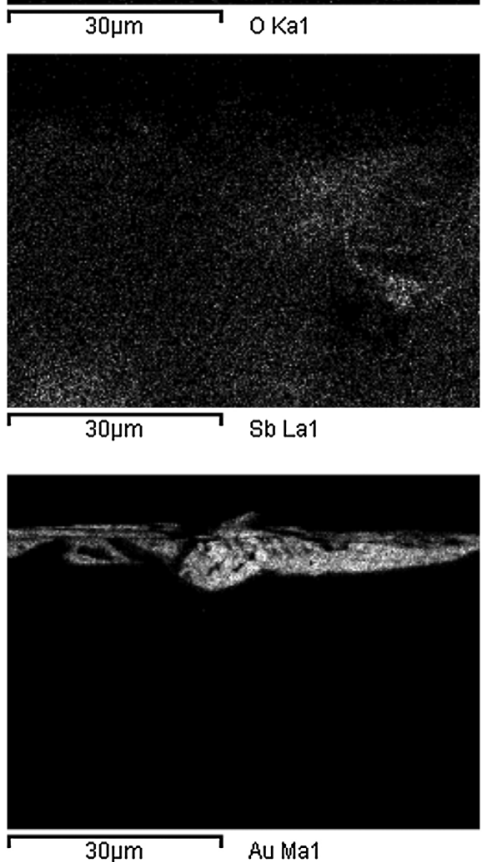
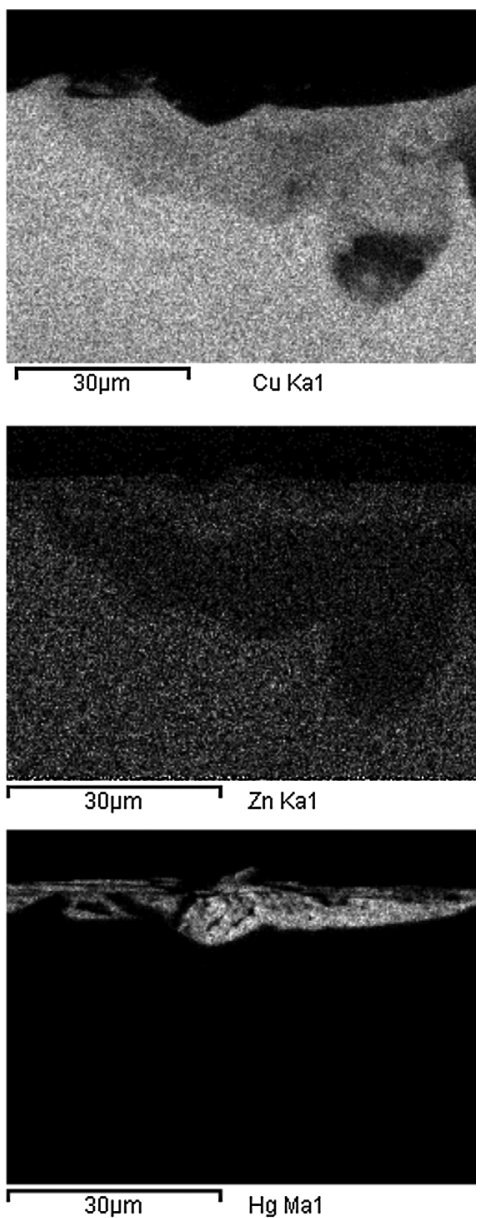

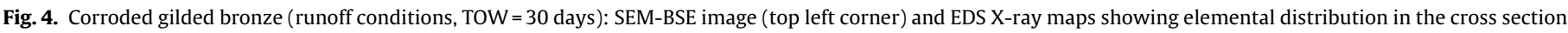
of a corrosion crater at the gold/bronze interface.

agreement with the GD-OES concentration profiles at $300-500 \mathrm{~nm}$ from the top surface (Fig. 3).

Inside the corrosion crater, the elements detected applying HRSRPES were $\mathrm{C}, \mathrm{O}, \mathrm{Cu}, \mathrm{Zn}, \mathrm{Sn}, \mathrm{Sb}$ and $\mathrm{Pb}$, while $\mathrm{S}$ and $\mathrm{Cl}$ were only found at trace levels and will not be considered in the following discussion.

HR-SRPES maps in Fig. 5 show the $\mathrm{Au}, \mathrm{Cu}, \mathrm{Sn}$ and $\mathrm{Pb}$ elemental distribution at a submicrometric scale. It is clearly revealed that the formation of the corrosion crater is related to a discontinuity within the gold layer, as shown by the Au map. Another important point is that $\mathrm{Sn}$ and $\mathrm{Cu}$ HR-SRPES maps clearly highlight a $\mathrm{Sn}$ relative enrichment induced by decuprification (internal oxidation of the bronze and Cu selective dissolution [58]). Decuprification is demonstrated also by measurements of $\mathrm{Cu}$ release in the ageing solutions, reported in $[5,59]$.

Moreover, the $\mathrm{Pb}$ map in Fig. 5 confirms that $\mathrm{Pb}$ is still present in the Au-rich layer after corrosion.

More detailed chemical information on the elements species involved in the corrosion layers inside the crater was obtained from core level analysis. In particular, quantification from core levels was 


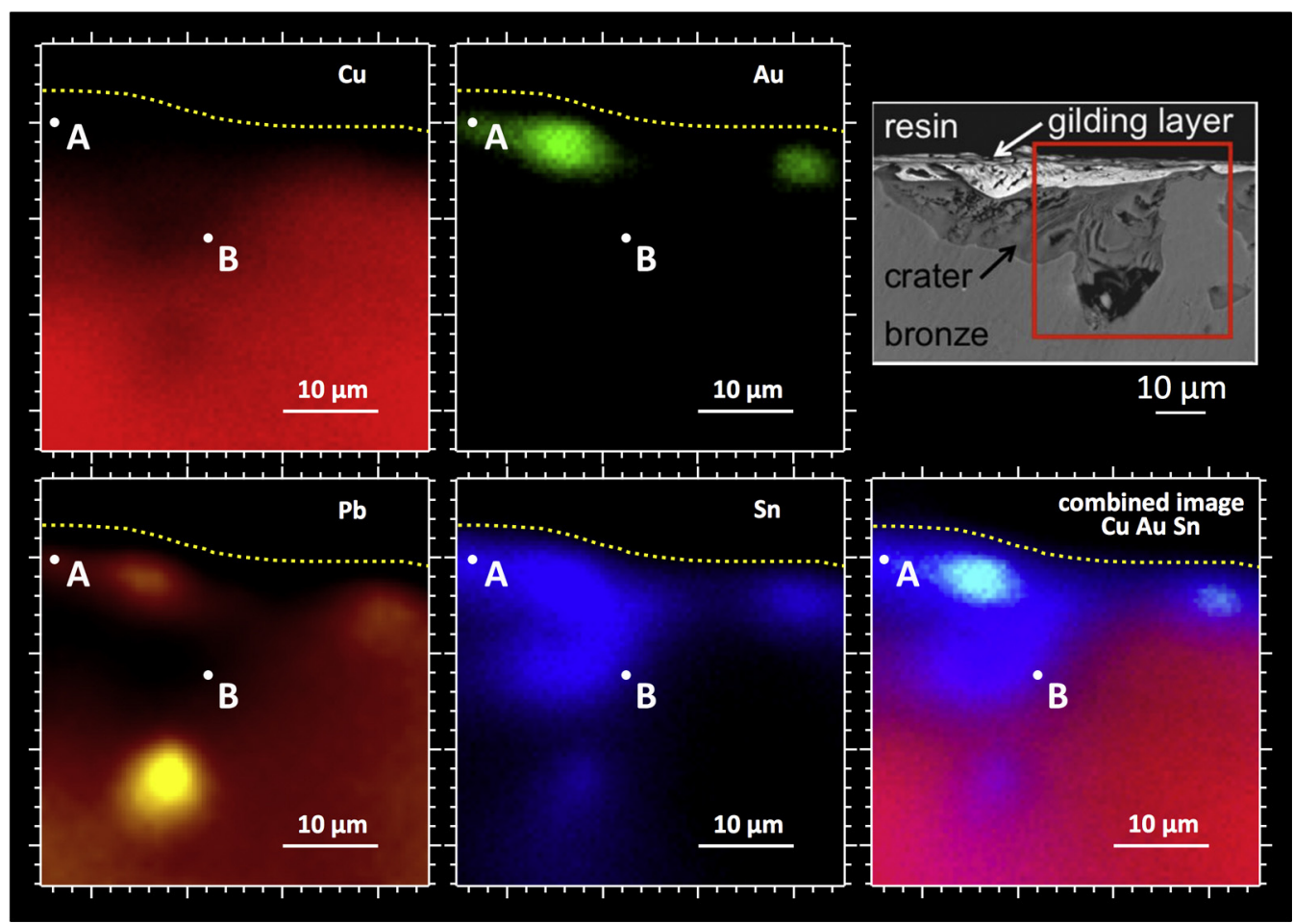

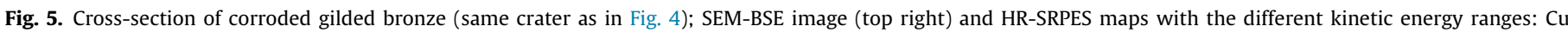

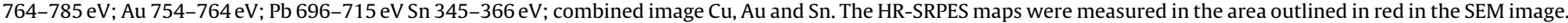
The dotted line marks the mounting resin/gilding layer interface.

Table 3

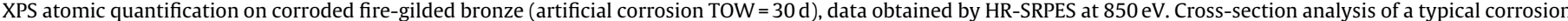

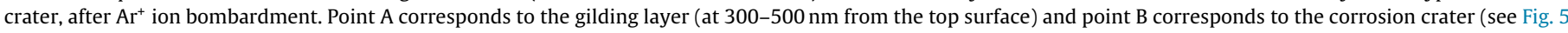
for the localisation of points in the maps). Each value has been normalised to Au atomic content $(\mathrm{Au}=1)$.

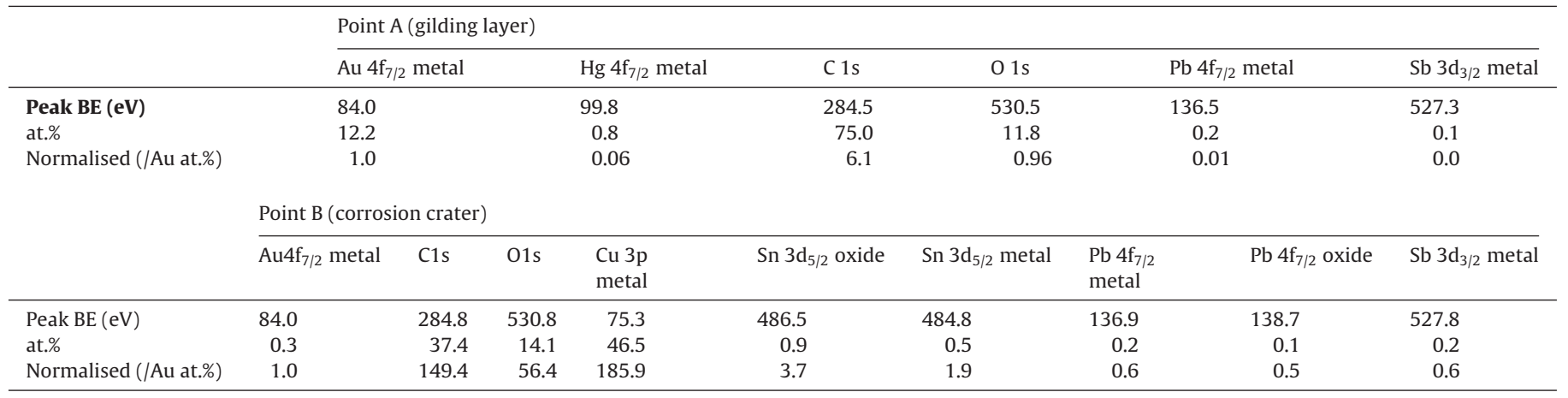

performed on point B located inside the crater (Fig. 5) and atomic quantification results are reported in Table 3. A precise attribution and deconvolution of the curves was complex, not only due to the presence of numerous species, but also because prolonged $\mathrm{Ar}^{+}$cleaning, carried out in order to reduce carbon contamination from the mounting resin, induced an important effect of reduction, according to the atomic balance obtained from core levels analysis for point B (Table 3). It was also revealed that Au was detected in a very low amount, probably linked to the metallographical preparation.

A representative example of the influence of $\mathrm{Ar}^{+}$cleaning can be observed in HR-SRPES maps for Sn species in the corrosion crater, reported in Fig. 7(a-c). Analysis of core level spectra showed that the main contribution was due to oxidised Sn species ( $\mathrm{Sn}(\mathrm{ox})$; BE at $486.5 \mathrm{eV}$ ), likely to be ascribed to the highest oxidation state $(+4)$. It also revealed the presence of $\mathrm{Sn}$ in its metallic state (BE $484.8 \mathrm{eV})$. As also metallic $\operatorname{Sn}(0)$ was identified inside the corrosion crater, this chemical state should be considered as an artefact due to a partial reduction of oxidised $\mathrm{Sn}$, linked to the $\mathrm{Ar}^{+}$cleaning step. This kind of artefact was already observed by other authors: the reduction phenomenon was also observed for $\mathrm{Pb}[21,40,42,60]$, but possibly also for $\mathrm{Cu}(3 \mathrm{p})[22,26]$.

In the same area, $\mathrm{O}$ bonded with $\mathrm{C}$ was detected within the corrosion crater, as shown in Fig. 8. Also, a remarkable effect of carbon pollution with a high intensity corresponding to several $\mathrm{C}-\mathrm{C}$ and $\mathrm{C}-\mathrm{O}(284.8 \mathrm{eV}$ and $286.2 \mathrm{eV})$ compounds was observed, likely due to mounting resin contamination. Thus, unfortunately, in this case, a precise attribution of peaks from specific binding energies was not achievable. For point B (Fig. 5, Table 3), based on the core level spectrum (Fig. 8d), the 01s region was fitted with three peaks at about $\mathrm{BE}=529.8 \mathrm{eV}\left(\mathrm{O}^{2-}\right), \mathrm{BE}=531.7-531.8 \mathrm{eV}\left(\mathrm{OH}^{-}, \mathrm{O}=\mathrm{C}-\mathrm{O}\right)$ and $\mathrm{BE}=533.1 \mathrm{eV}\left(\mathrm{C}-\mathrm{O}\right.$ and $\left.\mathrm{H}_{2} \mathrm{O}\right)$ [61]. The spatial distribution of each oxygen species was reported in HR-SRPES maps of Fig. 8a-c. In this case, the maps showed that on increasing depth, the low-BE 


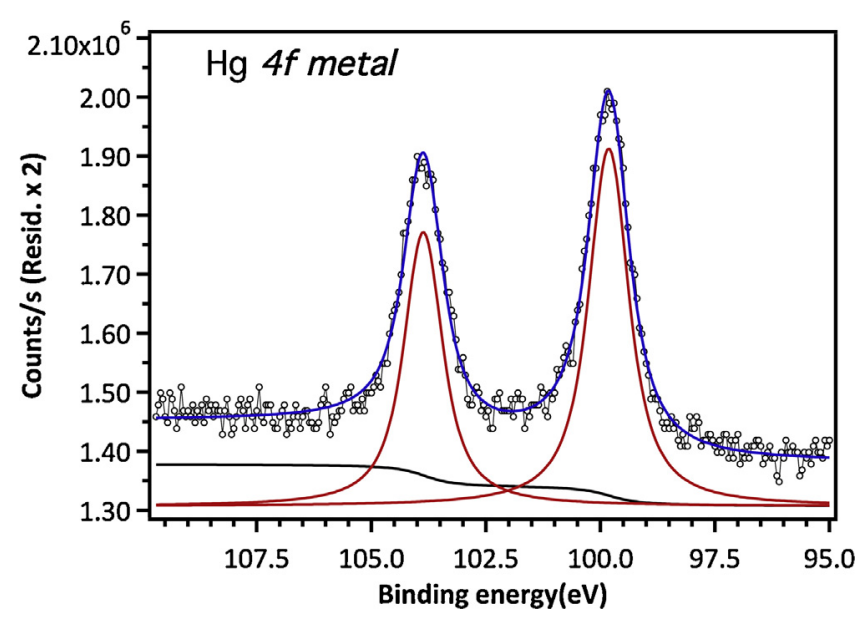

Fig. 6. $\mathrm{Hg} 4 \mathrm{f}_{7 / 2}$ curve-fitted regions within the gold layer (at around $300-500 \mathrm{~nm}$ from the top surface (point A in Fig. 5) - corroded gilded bronze - cross-section).

component gains intensity at the expense of high-BE components. In particular, $\mathrm{H}_{2} \mathrm{O}(533.1 \mathrm{eV})$ is mainly located in the upper layers of the crater (nearer to the metal/environment interface), whilst $\mathrm{OH}^{-}$ $(531.7 \mathrm{eV})$ and $\mathrm{O}^{2-}(529.8 \mathrm{eV})$ concentrate in the most internal layers. The presence of a widespread distribution of $\mathrm{OH}^{-}$can be also related to the contamination of the mounting resin (because of the overlapping of signals from $\mathrm{O}=\mathrm{C}-\mathrm{O}$ bonds in the resin with $\mathrm{OH}^{-}$
[61]). By comparison to the expected metallic oxidised species, the amount of oxygen is very high, probably due to the above mentioned contamination effects (different $\mathrm{O}-\mathrm{C}$ linked to $\mathrm{O}-\mathrm{H}$ bonds were detected).

However, even if special care has to be taken when preparing sample in order to avoid such contamination effects, the combined image in Fig. 8e allows to highlight the spatial distribution of different oxygen species throughout the corrosion crater. Interestingly, it shows that the main species within the crater, involved in the corrosion process, could be related to the formation hydroxi-oxide compounds rather than to pure oxide. For bronze ( $\mathrm{Cu}-\mathrm{Sn}$ alloys), this has to be related to the oxidation of the alloy, linked with the selective dissolution of the main alloying elements. As pointed out in case of atmospheric corrosion [62], but also in case of anodic corrosion [30] which is typically the case of galvanic coupling with gold, Sn species are not dissolved in the environment but remain in the inner layer as an insoluble product which is suspected to be (hydrated) hydroxi-oxides [62]. These species are supposed to form a network as for Sn oxide xerogel, through which copper ions and anions migrate towards the surface [30].

Fig. 8 HR-SRPES maps of a corrosion crater of a fire-gilded bronze (same as for Fig. 4). Oxygen spatial distribution (O 1s) measured at different kinetic energy ranges: (d) core level of Oxygen 1s corresponding to a typical point in the crater corrosion (point $\mathrm{B}$ in Fig. 5), revealing different binding energies in relation with different chemical states and (a) $\mathrm{O}^{2-} 313.8-315.0 \mathrm{eV}$; (b) $\mathrm{OH}^{-}$and $\mathrm{O}=\mathrm{C}-\mathrm{O} 313.0-313.8 \mathrm{eV}$; (c) $\mathrm{C}-\mathrm{O}$ and $\mathrm{H}_{2} \mathrm{O} 310.8-312 \mathrm{eV}$, so as to

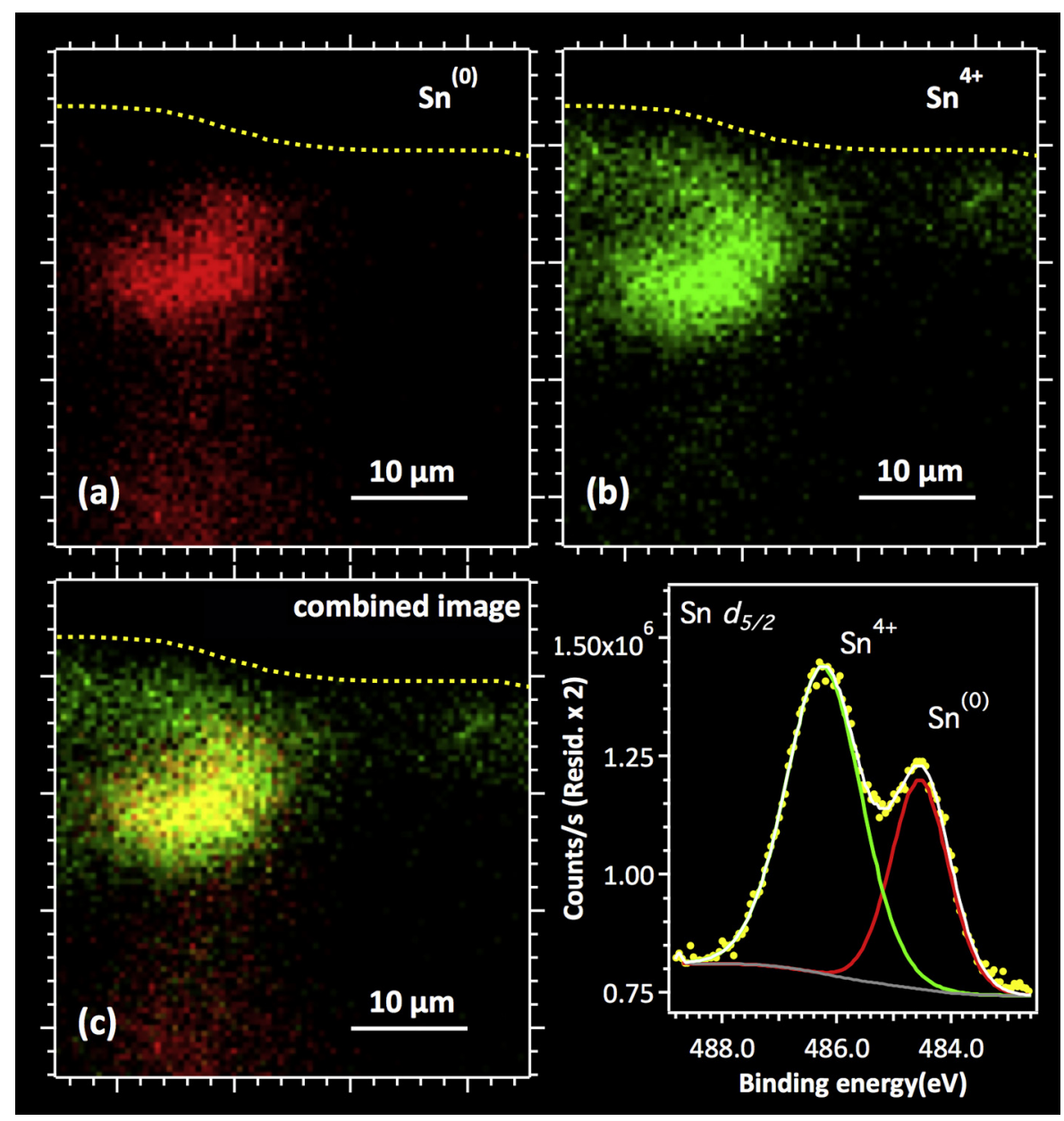

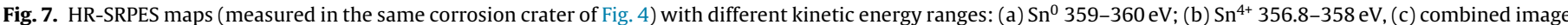

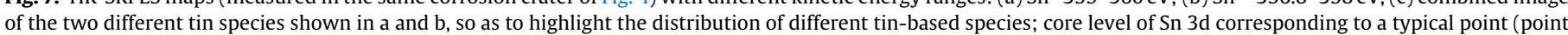
$\mathrm{B}$ in Fig. 5) in the corrosion crater, revealing different binding energies in relation with different chemical states. 


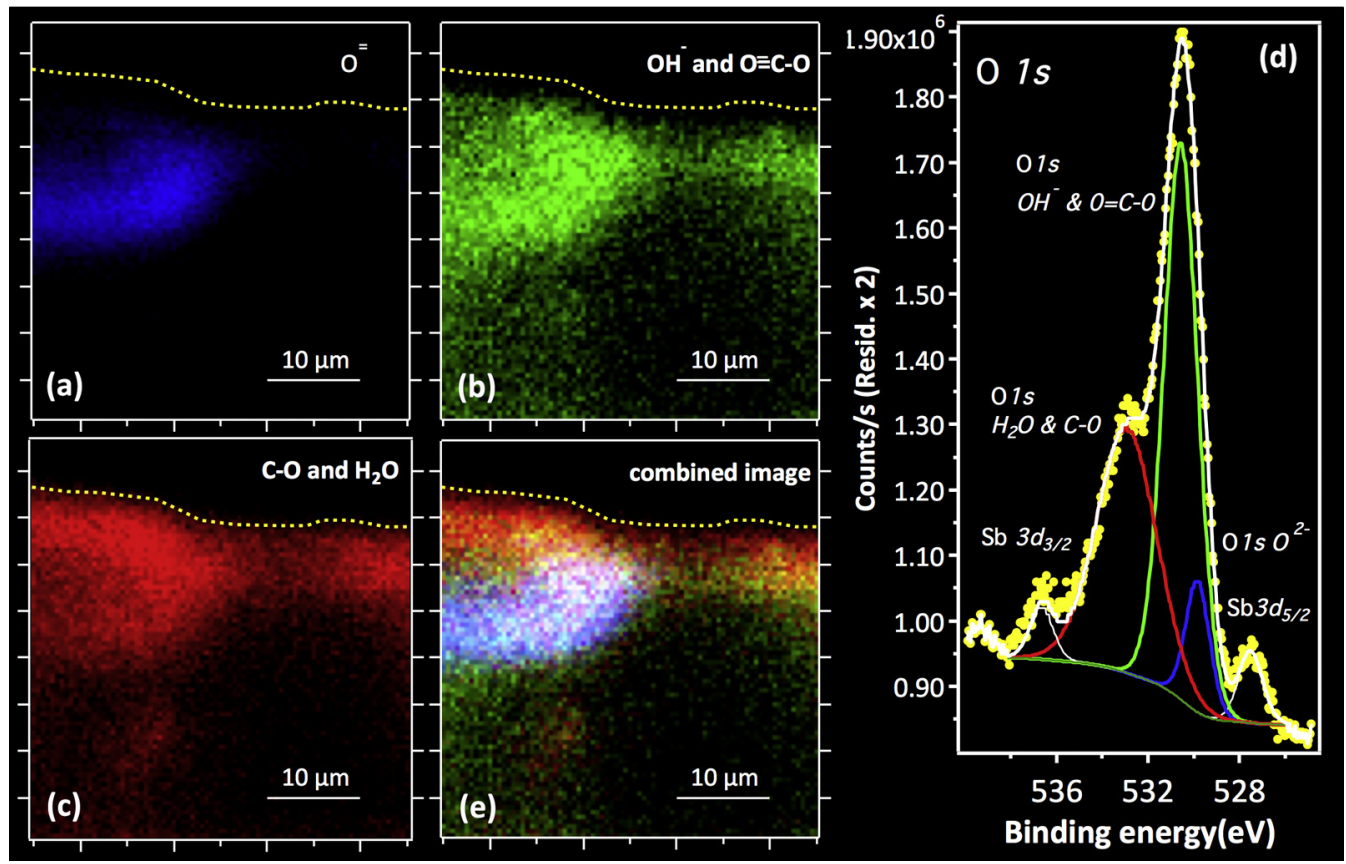

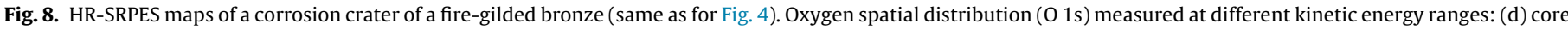

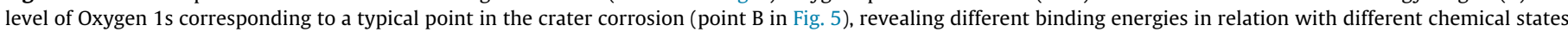

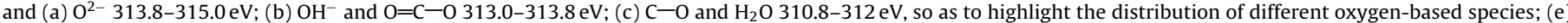
combined image of the three different oxygen species shown in $(a-b-c)$.

highlight the distribution of different oxygen-based species; (e) combined image of the three different oxygen species shown in $\mathrm{a}-\mathrm{b}-\mathrm{c}$.

\section{Conclusions}

The spatially resolved application of synchrotron radiation highresolution photoelectron spectroscopy (HR-SRPES) was found to be very promising for understanding complex structure as those found on cultural heritage metallic materials. Contamination due to mounting resin and consequent element reduction due to sputter cleaning here were identified as a main critical issues.

From this investigation of artificially corroded fire-gilded bronze, several main conslusions can be drawn:

- Heating during the fire-gilding procedure has been found to induce a remarkable enrichment in Sn and $\mathrm{Zn}$ in the top part of the gilded layer. This new result has to be carefully taken into account for conservation purposes of these bronzes, as these chemical elements usually exhibit different corrosion behaviour in outdoor conditions.

- HR-SRPES, applied for the first time on corroded gilded bronze, allowed detailed mapping of the spatial distribution and oxidation state of elements such as Sn and O.

- Metallic phases including $\mathrm{Hg}$ and $\mathrm{Pb}$ still remain in the gilding after corrosion.

- Selective dissolution of $\mathrm{Cu}$ and also $\mathrm{Zn}$ occurred in the corrosion craters due to galvanic coupling, which induces relative $\mathrm{Sn}$ species enrichment (decuprification).

- The distribution mapping of the chemical states revealed the formation of hydroxi-oxide compounds of Sn and O.

\section{Acknowledgements}

This research has been financially supported by PRIN 2009 MIUR Funds (Italy), grant number is 2009L55TFF_003. The financial support of Emilia-Romagna Region, Italy (POR-FESR funds) as well as of the FP7-CALIPSO (Coordinated Access to Lightsources to Promote Standards and Optimisation), grant number is 20140530 Transnational Access Programme is gratefully acknowledged. The authors wish to thank: Mr. Alessandro Pacini (Montepulciano, Italy) for producing fire-gilded bronzes according to ancient recipes (https://sites.google.com/site/archeometallurgia/). Dr. Iuri Boromei, at Dept. Industrial Engineering, University of Bologna, for his valuable help in sample preparation and for SEM/EDS investigations. All the personnel from the SOLEIL synchrotron facility and the IPANEMA laboratory (Gif Sur Yvette, France) is gratefully acknowledged for their very effective technical support.

\section{References}

[1] E. Darque-Ceretti, M. Aucouturier, Gilding for matter decoration and sublimation. A brief hisotry of the artisanal technical know-how, Int. J. Conserv. Sci. 4 (2013) 647-660.

[2] M. Grimwade, The surface enrichment of carat gold alloys-depletion gilding, Gold Technol. 26 (1999) 16-23.

[3] W.A. Oddy, Gilding of metals in the old world, in: S. La Niece, P. Craddock (Eds.), Met. Plat. Patination, Butterworth-Heinemann, Oxford, UK, 1993, pp. $171-181$.

[4] K. Anheuser, The practice and characterization of historic fire gilding techniques, JOM 49 (1997) 58-62, http://dx.doi.org/10.1007/s11837-9970015-6.

[5] C. Chiavari, E. Bernardi, A. Balbo, C. Monticelli, S. Raffo, M.C. Bignozzi, et al., Atmospheric corrosion of fire-gilded bronze: corrosion and corrosion protection during accelerated ageing tests, Corros. Sci. 100 (2015) 435-447.

[6] E. Mello, The gilding of Lorenzo Ghiberti's “Doors of Paradise; Gold Bull. 19 (1986) 123-126.

[7] V. Alunno Rossetti, M. Marabelli, Analyses of the patinas of a gilded horse of St Mark's Basilica in Venice: corrosion mechanisms and conservation problems, Stud. Conserv. 21 (1976) 161-170.

[8] P. Fiorentino, M. Marabelli, M. Matteini, A. Moles, The condition of the "Door of Paradise" by L. Ghiberti. Tests and proposals for cleaning, Stud. Conserv. 27 (1982) 145-153.

[9] G. Alessandrini, G. Dassù, P. Pedeferri, G. Re, On the conservation of the Baptistery doors in Florence, Stud. Conserv. 24 (1979) 108-124.

[10] S. Siano, R. Salimbeni, The Gate of Paradise: Physical optimization of the laser cleaning approach, Stud. Conserv. 46 (2001) 269-281. 
[11] A. Giusti, M. Matteini, The gilded bronze Paradise Doors by Ghiberti in the florence baptistery: scientific investigation and problems of restoration, in: Int. Conf. Met. Restor., 1997

[12] B. Mazza, P. Pedeferri, G. Re, D. Sinigaglia, Effectiveness of some inhibitors on the atmospheric corrosion of gold plated bronzes, in: Fourth Eur. Symp. Corros. Inhib., Annal. Univ. Ferrara, Ferrara, Italy, 1975, pp. 552-563.

[13] B. Mazza, P. Pedeferri, G. Re, D. Sinigaglia, Behaviour of a galvanic cell simulating the atmospheric corrosion conditions of gold plated bronzes, Corros. Sci. 17 (1977) 535-541.

[14] S. Siano, R. Salimbeni, R. Pini, A. Giusti, M. Matteini, Laser cleaning methodology for the preservation of the Porta del Paradiso by Lorenzo Ghiberti, J. Cult. Herit. 4 (2003) 140-146.

[15] M. Matteini, C. Lalli, I. Tosini, A. Giusti, S. Siano, Laser and chemical cleaning tests for the conservation of the Porta del Paradiso by Lorenzo Ghiberti, J. Cult. Herit. 4 (2003) 147-151

[16] S. Goidanich, D. Gulotta, L. Brambilla, R. Beltrami, P. Fermo, L. Toniolo, Setup of galvanic sensors for the monitoring of gilded bronzes, Sensors (Basel). 14 (2014) 7066-7083.

[17] M. Marabelli, The monument of Marcus Aurelius: research and conservation, in: D.A. Scott, J. Podany, B. Considine (Eds.), Anc. Hist. Met. Conserv. Sci. Res., The Getty Conservation Institute, 1994.

[18] C. Giavarini, M.L. Santarelli, Gli studi per la protezione del Marco Aurelio Mater. E Strutt. 6 (1996) 137-146.

[19] E. Bernardi, C. Chiavari, B. Lenza, C. Martini, L. Morselli, F. Ospitali, et al., The atmospheric corrosion of quaternary bronzes: the leaching action of acid rain, Corros. Sci. 51 (2009) 159-170.

[20] F. Garbassi, E. Mello, Surface spectroscopic studies on patinas of ancient metal objects, Stud. Conserv. 29 (1984) 172-180.

[21] E. Paparazzo, L. Moretto, Surface and interface microchemistry of archaeological objects studied with x-ray photoemission spectroscopy and scanning Auger microscopy, J. Electron Spectrosc. Relat. Phenom. 76 (1995 653-658.

[22] E. Paparazzo, L. Moretto, X-ray photoelectron spectroscopy and scanning Auger microscopy studies of bronzes from the collections of the Vatican Museums, Vacuum 55 (1999) 59-70.

[23] W. Liu, X. Cao, Y. Zhu, L. Cao, Effect of dopants on the electronic structure of $\mathrm{SnO}_{2}$ thin film, Sens. Actuators, B: Chem. 66 (2000) 219-221.

[24] E. Paparazzo, Organic substances at metal surfaces: archaeological evidence and the elder Pliny's account, Sci. Technol. 4 (2003) 615-624.

[25] R. Schlesinger, H. Klewe-Nebenius, M. Bruns, Characterization of artificially produced copper and bronze patina by XPS, Surf. Interface Anal. 30 (2000) 135-139.

[26] M.C. Squarcialupi, G.P. Bernardini, V. Faso, A. Atrei, G. Rovida, Characterisation by XPS of the corrosion patina formed on bronze surfaces, J. Cult. Herit. 3 (2002) 199-204

[27] M. Wadsak, T. Aastrup, I. Odnevall Wallinder, C. Leygraf, M. Schreiner, Multianalytical in situ investigation of the initial atmospheric corrosion of bronze, Corros. Sci. 44 (2002) 791-802.

[28] M. Chan, A. Capek, D.A. Brill, S.J. Garrett, Characterization of the patina formed on a low tin bronze exposed to aqueous hydrogen sulfide, Surf. Interface Anal. 46 (2014) 433-441.

[29] C. Debiemme-Chouvy, F. Ammeloot, E.M.M. Sutter, X-ray photoemission investigation of the corrosion film formed on a polished $\mathrm{Cu}-13 \mathrm{Sn}$ alloy in aerated NaCl solution, Appl. Surf. Sci. 174 (2001) 55-61.

[30] L. Robbiola, T.T.M. Tran, P. Dubot, O. Majerus, K. Rahmouni, Characterisation of anodic layers on $\mathrm{Cu}-10 \mathrm{Sn}$ bronze (RDE) in aerated $\mathrm{NaCl}$ solution, Corros. Sci. 50 (2008) 2205-2215, http://dx.doi.org/10.1016/j.corsci.2008.06.003.

[31] M. Yokota, F. Sugaya, H. Mifune, Y. Kobori, K. Shimizu, K. Nakai, et al., Possibility of bacteria-induced corrosion of ancient bronze mirrors found in ground, Mater. Trans, 44 (2003) 268-276.

[32] M.P. Casaletto, T. De Caro, G.M. Ingo, C. Riccucci, Production of reference "ancient" Cu-based alloys and their accelerated degradation methods, Appl. Phys. A: Mater. Sci. Process. 83 (2006) 617-622.

[33] M.P. Casaletto, G.M. Ingo, C. Riccucci, F. Faraldi, Production of reference alloys for the conservation of archaeological silver-based artifacts, Appl. Phys. A: Mater. Sci. Process. 100 (2010) 937-944.

[34] I.Z. Balta, S. Pederzoli, E. Iacob, M. Bersani, Dynamic secondary ion mas spectrometry and X-ray photoelectron spectroscopy on artistic bronze and copper artificial patinas, Appl. Surf. Sci. 255 (2009) 6378-6385

[35] K. Trentelman, L. Stodulski, D.A. Scott, M. Back, S. Stock, D. Strahan, et al., The characterization of a new pale blue corrosion product found on copper alloy artifacts, Stud. Conserv. 47 (2002) 217-227.

[36] A. Salvi, F. Langerame, A. Macchia, M. Sammartino, M. Tabasso, XPS characterization of (copper-based) coloured stains formed on limestone surfaces of outdoor Roman monuments, Chem. Cent. J. 6 (2012) S10.
[37] Y. Zhu, D. Li, B. Shi, L. Wan, F. Xu, B. Tao, The films on bronze surface formed by AMT composite regent through XPS and AES methods, Corros. Sci. Prot. Technol. 12 (2000) 24-26.

[38] A. Galtayries, A. Mongiatti, P. Marcus, C. Chiavari, Surface characterisation of corrosion inhibitors on bronzes for artistic casting, Corr. of Herit. Artefacts, Book 48 (2007) 335-350

[39] A. Daccà, P. Prati, A. Zucchiatti, F. Lucarelli, P.A. Mandò, G. Gemme, et al., Combined PIXE and XPS analysis on republican and imperial Roman coins, Nucl. Instrum. Methods Phys. Res. Sect. B: Beam Interact. Mater. At. 161 (2000) 743-747.

[40] G.M. Ingo, E. Angelini, T. De Caro, G. Bultrini, A. Mezzi, Combined use of XPS and SEM + EDS for the study of surface microchemical structure of archaeological bronze Roman mirrors, Surf. Interface Anal. 36 (2004) 871-875

[41] P. Northover, A. Crossley, C. Grazioli, N. Zema, S. La Rosa, L. Lozzi, et al., A multitechnique study of archeological bronzes, Surf. Interface Anal. 40 (2008) 464-468.

[42] L. Lozzi, P. Picozzi, N. Zema, C. Grazioli, A. Crossley, P. Northover, et al., A multitechnique study of archaeological bronzes: Part II, Surf. Interface Anal. 43 (2010) 1120-1127.

[43] A. Mezzi, T. De Caro, C. Riccucci, F. Faraldi, C. Veroli, D. Caschera, Unusual surface degradation products grown on archaeological bronze artefacts, Appl. Phys. A: Mater. Sci. Process. 113 (2013) 1121-1128.

[44] F. Caridi, A.M. Mezzasalma, E.D. Castrizio, An investigation on the patina of ancient bronze coins, Radiat. Eff. Defects Solids 169 (2014) 371-379.

[45] G.M. Ingo, G. Guida, E. Angelini, G. Di Carlo, A. Mezzi, G. Padeletti, Ancient mercury-based plating methods: combined use of surface analytical techniques for the study of manufacturing process and degradation phenomena, Acc. Chem. Res. 46 (2012) 2365-2375.

[46] A. Crabbé, M.A. Languille, I. Vandendael, J. Hammons, M.G. Silly, G. Dewanckel, et al., Colorando Auro: Contribution to the understanding of a medieval recipe to colour gilded silver plates, Appl. Phys. A: Mater. Sci. Process. 111 (2013) 39-46.

[47] A. Balbo, C. Chiavari, C. Martini, C. Monticelli, Effectiveness of corrosion inhibitor films for the conservation of bronzes and gilded bronzes, Corros. Sci. 59 (2012) 204-212.

[48] B. Cellini, I trattati dell'oreficeria e della scultura, secondo il codice Marciano, Hoepli, Milano, 1927.

[49] J. Avila, I. Razado-Colambo, S. Lorcy, J.-L. Giorgetta, F. Polack, M.C. Asensio, Interferometer-controlled soft X-ray scanning photoemission microscope at SOLEIL, J. Phys. Conf. Ser. 425 (2013) 132013.

[50] J. Avila, I. Razado-Colambo, S. Lorcy, B. Lagarde, J.-L. Giorgetta, F. Polack, et al., ANTARES, a scanning photoemission microscopy beamline at SOLEIL, J. Phys. Conf. Ser. 425 (2013) 192023

[51] C.W. Chang, Q.P. Lee, C.E. Ho, C.R. Kao, Cross-interaction between Au and Cu in $\mathrm{Au} / \mathrm{Sn} / \mathrm{Cu}$ ternary diffusion couples, J. Electron. Mater. 35 (2006) 366-371

[52] M.R. Pinnel, Diffusion-related behaviour of gold in thin film systems, Gold Bull. 12 (1979) 62-71.

[53] E. Figueiredo, R.J.C. Silva, M.F. Araújo, J.C. Senna-Martinez, Identification of ancient gilding technology and Late Bronze Age metallurgy by EDXRF, Micro-EDXRF, SEM-EDS and metallographic techniques, Microchim. Acta. 168 (2010) 283-291.

[54] L. Selwyn, Corrosion chemistry of gilded silver and copper, in: Gilded Met. Hist. Technol. Conserv. Archetype Publications, London, UK, 2000, pp. 21-47.

[55] B. Feng, J. Weng, B.C. Yang, S.X. Qu, X.D. Zhang, Characterization of surface oxide films on titanium and adhesion of osteoblast, Biomaterials 24 (2003) 4663-4670.

[56] S. Colin, E. Beche, R. Berjoan, H. Jolibois, A. Chambaudet, An XPS and AES study of the free corrosion of $\mathrm{Cu}-, \mathrm{Ni}$ - and $\mathrm{Zn}$-based alloys in synthetic sweat, Corros. Sci. 41 (1999) 1051-1065.

[57] ASM International, Alloy Phase Diagrams-ASM Handbook, ASM International, 1992

[58] L. Robbiola, R. Portier, A global approach to the authentication of ancient bronzes based on the characterization of the alloy-patina-environment system, J. Cult. Herit. 7 (2006) 1-12.

[59] I. Mabille, A. Bertrand, E.M.M. Sutter, C. Fiaud, Mechanism of dissolution of a $\mathrm{Cu}-13 \mathrm{Sn}$ alloy in low aggressive conditions, Corros. Sci. 45 (2003) 855-866.

[60] E. Paparazzo, L. Moretto, X-ray photoemission study of soldered lead materials relevance to the surface and interface chemical composition of Roman lead pipes “fistulae; Vacuum 49 (1998) 125-131.

[61] E. Cano, J.M. Bastidas, J.L. Polo, N. Mora, Study of the effect of acetic acid vapor on copper corrosion at 40 and 80\% relative humidity, J. Electrochem. Soc. 148 (2001) B431.

[62] C. Chiavari, K. Rahmouni, H. Takenouti, S. Joiret, P. Vermaut, L. Robbiola, Composition and electrochemical properties of natural patinas of outdoor bronze monuments, Electrochim. Acta. 52 (2007) 7760-7769. 